Check for updates

Cite this: RSC Adv., 2018, 8, 32775

Received 13th June 2018

Accepted 6th September 2018

DOI: 10.1039/c8ra05083j

rsc.li/rsc-advances

\section{Corroboration of $\mathrm{Zn(II)-Mg(II)-tertiary} \mathrm{structure}$ interplays essential for the optimal catalysis of a phosphorothiolate thiolesterase ribozyme $\uparrow$}

\author{
Tzu-Pin Wang, (DD *ab Yu-Chih Su, $\dot{t}^{\mathrm{a}}$ Yi Chen, $\dot{t}^{\mathrm{a}}$ Scott Severance, ${ }^{c}$ Chi-Ching Hwang, ${ }^{d}$ \\ Yi-Ming Liou, ${ }^{a}$ Chia-Hui Lu, ${ }^{a}$ Kun-Liang Lin, ${ }^{a}$ Rui Jing Zhu ${ }^{a}$ and Eng-Chi Wang ${ }^{a}$
}

The TW17 ribozyme, a catalytic RNA selected from a pool of artificial RNA, is specific for the $\mathrm{Zn}^{2+}$ dependent hydrolysis of a phosphorothiolate thiolester bond. Here, we describe the organic synthesis of both guanosine $\alpha$-thio-monophosphate and the substrates required for selecting and characterizing the TW17 ribozyme, and for deciphering the catalytic mechanism of the ribozyme. By successively substituting the substrate originally conjugated to the RNA pool with structurally modified substrates, we demonstrated that the TW17 ribozyme specifically catalyzes phosphorothiolate thiolester hydrolysis. Metal titration studies of TW17 ribozyme catalysis in the presence of $\mathrm{Zn}^{2+}$ alone, $\mathrm{Zn}^{2+}$ and $\mathrm{Mg}^{2+}$, and $\mathrm{Zn}^{2+}$ and $\left[\mathrm{Co}\left(\mathrm{NH}_{3}\right)_{6}\right]^{3+}$ supported our findings that $\mathrm{Zn}^{2+}$ is absolutely required for ribozyme catalysis, and indicated that optimal ribozyme catalysis involves the presence of outer-sphere and one inner-sphere $\mathrm{Mg}^{2+}$. A survey of the TW17 ribozyme activity at various $\mathrm{pHs}$ revealed that the activity of the ribozyme critically depends on the alkaline conditions. Moreover, a GNRA tetraloop-containing ribozyme constructed with active catalysis in trans provided catalysis and multiple substrate turnover efficiencies significantly higher than ribozymes lacking a GNRA tetraloop. This research supports the essential roles of $\mathrm{Zn}^{2+}, \mathrm{Mg}^{2+}$, and a GNRA tetraloop in modulating the TW17 ribozyme structure for optimal ribozyme catalysis, leading also to the formulation of a proposed reaction mechanism for TW17 ribozyme catalysis.

\section{Introduction}

Catalytic RNAs (ribozymes) are versatile and powerful catalysts ${ }^{1,2}$ and frequently are used with metal ions in diverse catalytic strategies. ${ }^{2}$ The involvement of metal ions in ribozyme catalysis is intimately associated with the fundamental structure of RNA. At physiological pH, RNA molecules are essentially polyelectrolytes laden with negatively charged phosphate groups. To counteract electrostatic repulsion due to the phosphate moieties, RNA typically sequesters metal cations for proper folding - a process in which metal ions can specifically

\footnotetext{
${ }^{a}$ Department of Medicinal and Applied Chemistry, Kaohsiung Medical University, Kaohsiung, 80708, Taiwan. E-mail: tzupinw@kmu.edu.tw; Fax: +886-07-312-5339; Tel: $+886-07-312-1101$, ext. 2756

${ }^{b}$ Kaohsiung Medical University Hospital, Kaohsiung Medical University, Kaohsiung, 80708, Taiwan

'Department of Molecular and Cellular Sciences, Liberty University College of Osteopathic Medicine, Lynchburg, Va 24515, USA

${ }^{d}$ Department of Biochemistry, Kaohsiung Medical University, Kaohsiung, 80708, Taiwan

$\dagger$ Electronic supplementary information (ESI) available: Full details of supporting figures referenced in the text, NMR and MS spectra for some known and all the new compounds $(2,3,6,8 b, 9 a, 9 b, 10 a, 10 b, 15 b, 16 b, 17,18 a$, and $18 b)$. See DOI: $10.1039 / \mathrm{c} 8 \mathrm{ra} 05083 \mathrm{j}$

$\$$ Authors contributed equally to this study.
}

bind RNA ligands to further stabilize RNA structures. ${ }^{3}$ Additionally, RNA can specifically recruit divalent metal ions to play a direct role in the chemical mechanism of ribozyme catalysis. ${ }^{3,4}$ Conversely, some small nucleolytic ribozymes perform catalysis in the presence of molar concentrations of monovalent metal ions and in the absence of divalent metal ions. ${ }^{2,4-6}$ The catalytic abilities of these ribozymes can be attributed to the proton transfer involved in general acid-base catalysis ${ }^{7,8}$ and the presence of a disproportionate amount of interacting ions in the ion atmosphere surrounding nucleic acids. ${ }^{9-13}$ However, the detection of ribozyme catalysis at high concentrations of monovalent cations does not necessarily preclude a critical function for divalent cations in ribozyme catalysis because divalent metal ions are not required to directly contact any of the functional groups in the active site of a ribozyme in order to play an essential catalytic role. ${ }^{4}$ Thus, gaining a comprehensive understanding of the diverse mechanisms of ribozyme catalysis requires knowledge of the specific roles of divalent metal ions in catalysis-active ribozyme structures.

Among the divalent metal ions, $\mathrm{Mg}^{2+}$ is capable of specifically binding catalytic RNA by either direct inner-sphere coordination or indirect outer-sphere coordination in the presence of water ligands. ${ }^{4}$ Replacing $\mathrm{Mg}^{2+}$ with other metal ions can drastically alter the catalytic activity of ribozymes. Besides $\mathrm{Mg}^{2+}$, the $\mathrm{Zn}(\mathrm{II})$ ion also commonly participates in catalysis in 
biological systems and is the only divalent metal cofactor present in all six enzyme classes of the International Union of Biochemistry. ${ }^{14-17}$ Compared to $\mathrm{Mg}^{2+}, \mathrm{Zn}^{2+}$ has a higher phosphate monoester affinity but seldom plays a prominent role in ribozyme catalysis. This is likely due to a low concentration of free $\mathrm{Zn}^{2+}$ in vivo ${ }^{16}$ and the lower binding affinities of metal ions to ribozymes than to proteins. ${ }^{4}$ Nevertheless, identification of natural and nonnatural $\mathrm{Zn}^{2+}$-assisted or $\mathrm{Zn}^{2+}$-dependent nucleic acid enzymes could provide insights into the plausible functions of zinc in ribozyme catalysis. ${ }^{18}$

In addition to the integral roles of metal ions in RNA folding and its catalytic function, the tertiary RNA structure and function can be further supported by long-range interactions between RNA hairpins capped by GNRA (where $\mathrm{N}$ represents any nucleotide; $\mathrm{R}$ is a purine) tetraloops and their receptors, ${ }^{\mathbf{1 9 - 2 1}}$ including RNA motifs ${ }^{\mathbf{1 9 , 2 2}}$ and proteins. ${ }^{23}$ GNRA tetraloops were first identified in ribosomal RNA (rRNA) and are frequently used to cap RNA duplexes in rRNA. ${ }^{24}$ Thus, GNRA tetraloop-receptor interactions can be critical to optimizing the conformations and catalytic functions of ribozymes.

We previously described an in vitro selection of a novel ribozyme called the TW17 ribozyme, which catalyzes the hydrolysis of a phosphorothiolate thiolester bond in the presence of $\mathrm{Zn}^{2+}$ (Scheme 1). ${ }^{18}$ TW17 ribozyme catalysis demonstrated the indispensable role of $\mathrm{Zn}^{2+}$ as a cofactor and the requirement for the concomitant presence of $\mathrm{Zn}^{2+}$ and $\mathrm{Mg}^{2+}$ for the catalytic activity of this ribozyme. Herein, we describe the syntheses of guanosine $\alpha$-thio-monophosphate (6), the substrate (18b) used in the in vitro selection of the TW17 ribozyme, and the additional substrates that proved to be essential in elucidating the roles of $\mathrm{Zn}^{2+}$ and $\mathrm{Mg}^{2+}$ in the chemical mechanism of ribozyme catalysis. In addition, $\mathrm{pH}$ titration of the ribozyme catalysis unveiled the requirement for alkaline conditions in TW17 ribozyme catalysis. Finally, the importance of a GNRA tetraloop for optimal ribozyme catalysis was supported by enhanced ribozyme catalysis in a GNRA tetraloopretaining TW17 ribozyme construct with active catalysis in trans. Such critical information enabled the development of a proposed reaction mechanism of TW17 ribozyme catalysis in which the hydrolysis reaction is accelerated by an inner-spherecoordinated zinc(II) hydroxide in the ribozyme under alkaline conditions. This finding is reminiscent of the many catalytically important roles that $\mathrm{Zn}^{2+}$ ions play in zinc-dependent metalloenzymes ${ }^{\mathbf{1 4 , 1 5 , 1 7 , 2 5}}$ and thus suggests that ribozymes and protein enzymes could exploit similar zinc chemistry to effect chemical catalysis.

\section{Results}

\section{Synthesis of GMPS salts and substrates for selecting the TW17 ribozyme and for deciphering the ribozyme substrate specificity}

We initiated this study by synthesizing the more water-soluble ammonium salt of guanosine $\alpha$-thio-monophosphate $\left(\mathrm{NH}_{4}^{-}\right.$ GMPS, 6; Scheme 2). GMPS was incorporated into the $5^{\prime}$ end of RNA during round-off transcription by T7 RNA polymerase, which subsequently enabled the coupling of small substrate molecules to GMPS-primed RNA. The afforded substrate-RNA pool paved the way for enriching and selecting active RNA sequences, including the TW17 ribozyme. ${ }^{18}$

The synthesis of GMPS has been reported previously but often involving tedious and unconventional procedures. ${ }^{26-31} \mathrm{We}$ synthesized 6 from 1 by first protecting the $2^{\prime}$ and $3^{\prime}$ hydroxyl groups with acetone through ketal formation to afford 2 with an excellent yield (98\%, Scheme 2). ${ }^{32}$ We initially attempted to directly synthesize 6 by thiophosphorylating 2, producing an ammonium salt in the presence of $\mathrm{NH}_{4} \mathrm{OH}$, and finally, removing the acetone protection group to attain the desired 6 (the "]"-shaped arrow in Scheme 2). However, the synthesis of 6 was fruitless using this approach, primarily due to difficulties in recovering 6 from the reaction mixture. We also explored synthesizing 6 by thiophosphorylating 2, acquiring a sodium salt in the presence of $\mathrm{NaOH}$ and then deprotecting acetone to yield 3 (the sodium salt of GMPS; the curved arrow in Scheme 2),
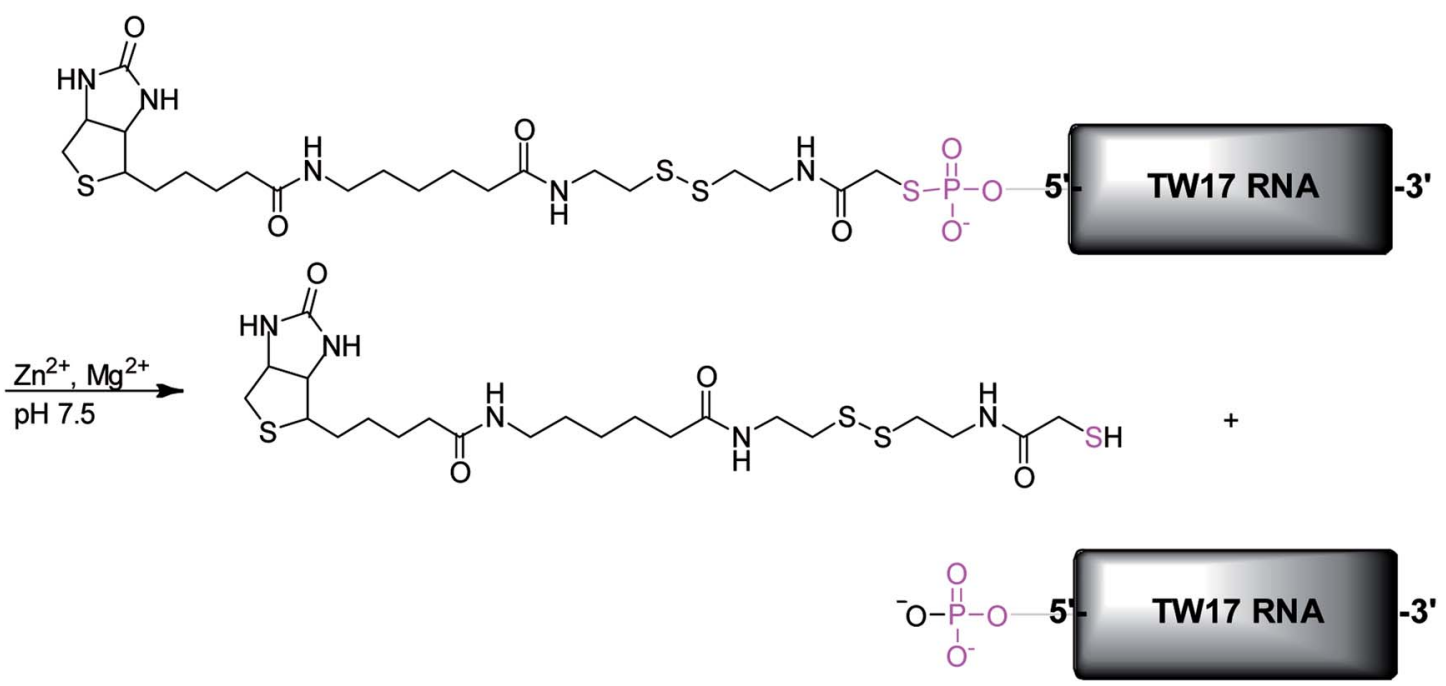

Scheme 1 The phosphorothiolate thiolester hydrolysis reaction catalyzed by the TW17 ribozyme. 


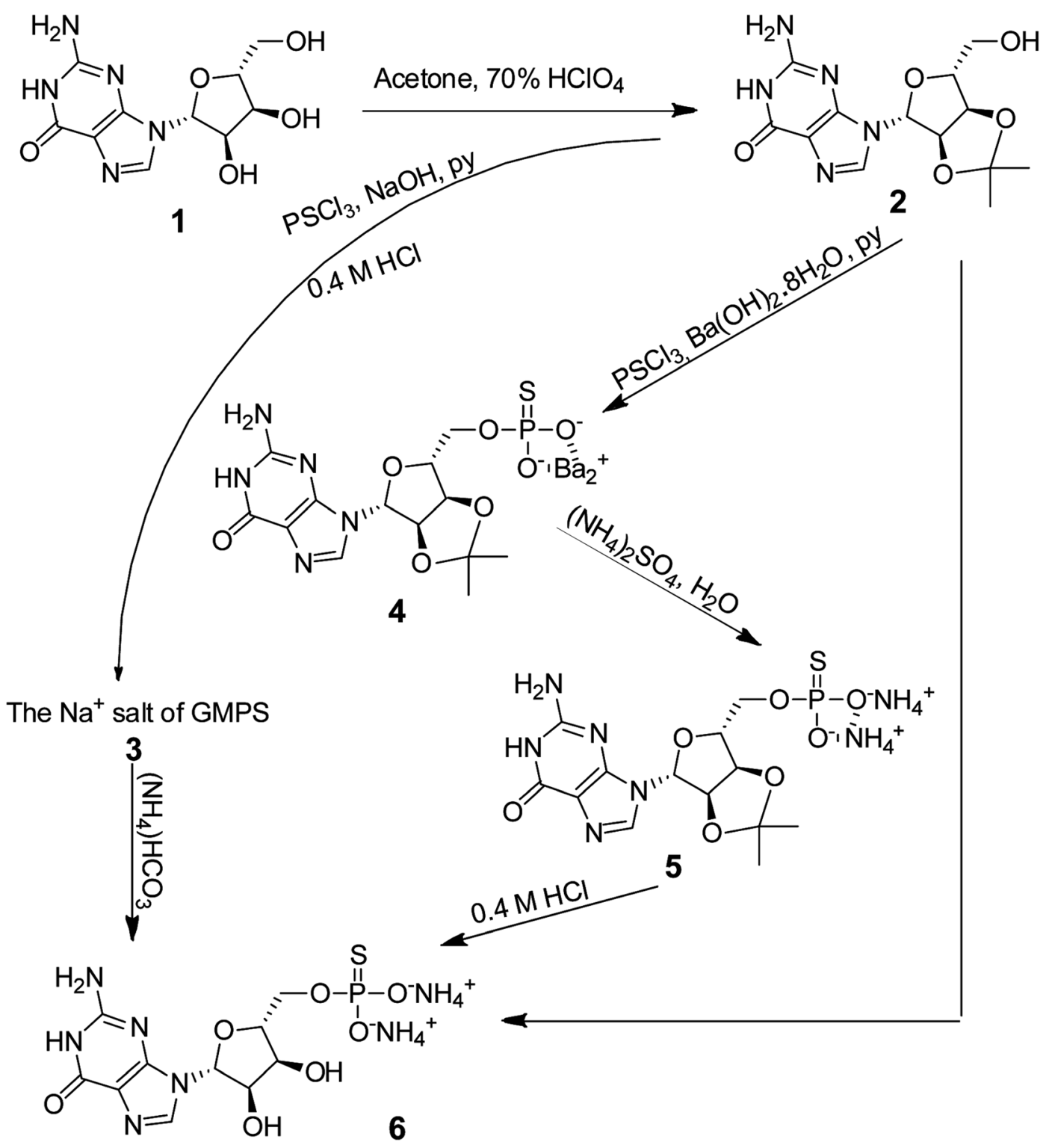

Scheme 2 Synthesis of the ammonium salt of guanosine $\alpha$-thio-monophosphate (6). Three routes for the synthesis of 6 were explored in this study. Only the route sequentially synthesizing 4 and 5 from 2 could produce 6 with a high yield (see text).

and finally subjecting 3 to an ion exchange reaction to obtain 6 in sequence. However, the yield of the reaction from 2 to 4 was too low $(25 \%)$ to make the synthesis of 6 practical.

Consequently, we decided to develop a more complicated but potentially more effective method to synthesize 6 (i.e., via the central route in Scheme 2). We first thiophosphorylated 2 in the presence of barium hydroxide, resulting in the formation of 4 with a good yield (75\%). The barium ion in 4 was then quantitatively exchanged with an ammonium ion to afford $\mathbf{5}$ (98\%), which was then subjected to removal of the acetone protection group and purification using a DEAE Sepharose Fast Flow column, sequentially, to produce the desired 6 (64\%). Analysis revealed that 6 was free of contamination by the ammonium salt of the potential guanosine monophosphate (GMP) by-product. Specifically, the ${ }^{31} \mathrm{P}$ NMR spectrum of 6 indicated the presence of GMPS $(\delta=43.65)$ without detecting
$\operatorname{GMP}(\delta=0)(\mathrm{ESI}, \dagger$ page S24). These results clearly demonstrated that 6 was effectively synthesized and that our method overcame the previously reported oxygen-sulfur exchange problem of the thiophosphate moiety in nucleotides. ${ }^{30,33}$ The overall yield of 6 from 1 using our synthesis approach was 46\%. Compound 6 was characterized and confirmed by both ${ }^{1} \mathrm{H}$ and ${ }^{13} \mathrm{C}$ NMR spectroscopy, while the molecular mass was confirmed by HRMS.

Successfully acquiring 6 allowed us to focus on synthesizing the ribozyme substrate indispensable to the ribozyme selection. The evolution and selection of ribozymes from the artificial RNA pool initially primed with 6 at the $5^{\prime}$ head were achieved by covalently tagging the molecules in the GMPS-primed RNA pool with a biotin-derivatized substrate through a phosphorothiolate thiolester bond (Scheme 3). Active RNA sequences could be separated from inactive sequences in the substrate-RNA pool by taking advantage of the high affinity interaction between biotin 
(A)
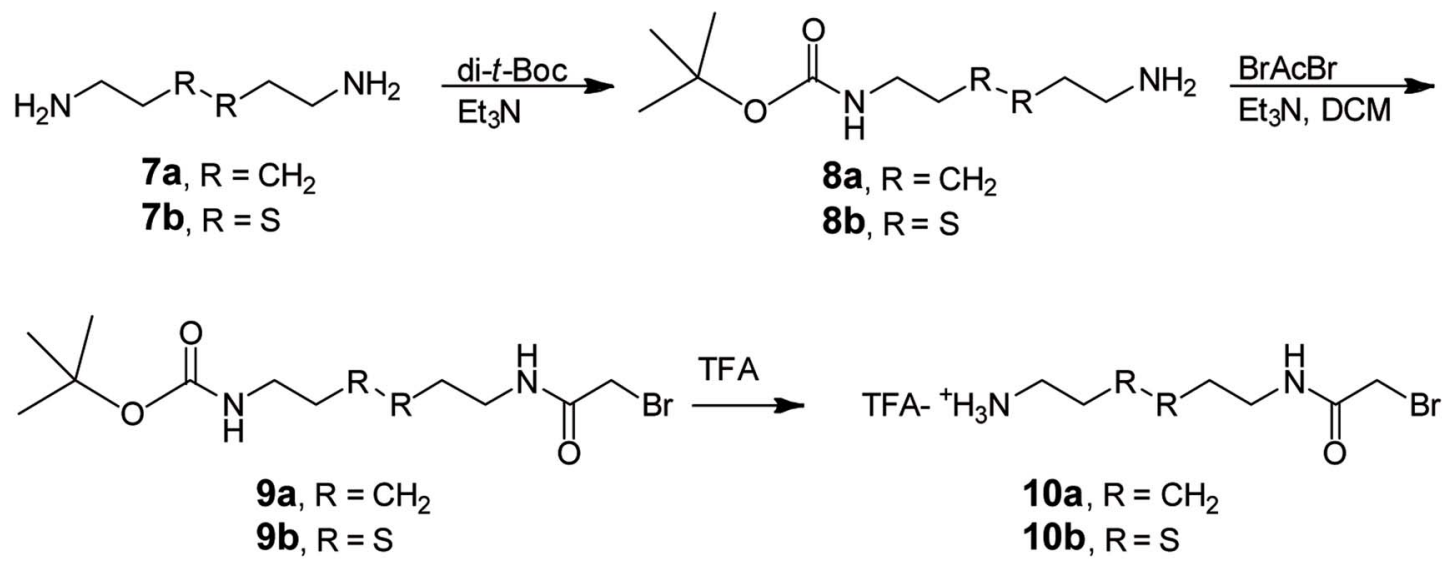

(B)

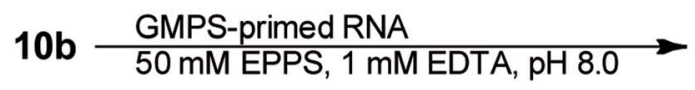
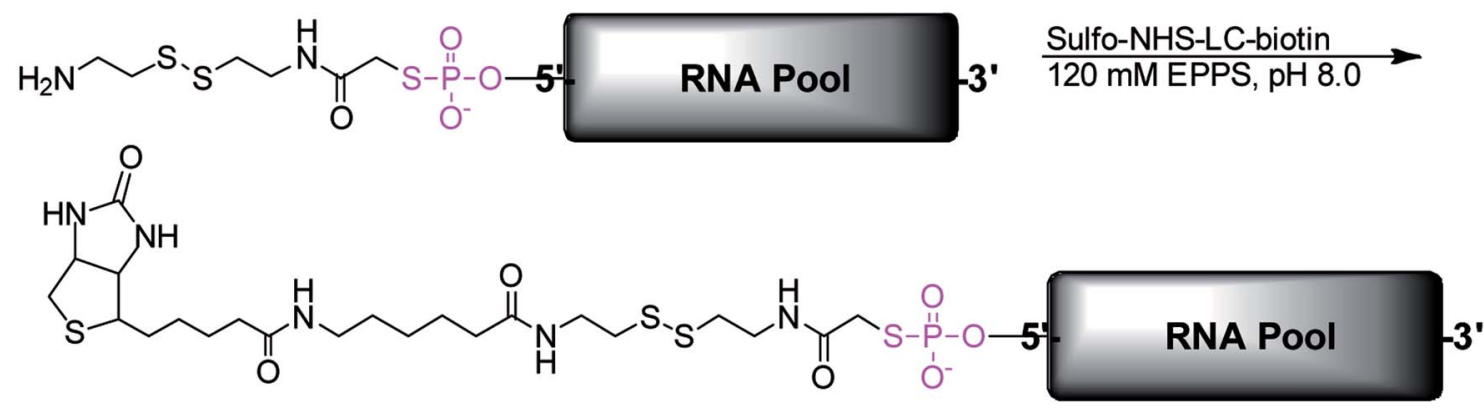

Scheme 3 Synthesis of substrates and substrate-RNA conjugates. (A) Synthesis of the substrates required for the in vitro selection of the TW17 ribozyme and the determination of the substrate specificity of the TW17 ribozyme. (B) Preparation of the substrate-RNA conjugates for in vitro evolution and selection of the TW17 ribozyme.

and streptavidin. ${ }^{18}$ To expedite the in vitro selection of the ribozymes, we prepared the required substrate-RNA pool by dissecting the biotin-containing substrate $\mathbf{1 8 b}$ (Scheme 4) into two segments. Each segment was covalently linked to the GMPSprimed random artificial RNA pool sequentially (Scheme 3B). Specifically, the 18b-RNA conjugates were synthesized by initially coupling the GMPS-primed RNA pool to the prosubstrate 10b and subsequently biotinylating the product with commercially available sulfo-NHS-LC-biotin to generate the 18b-RNA pool used in each in vitro selection cycle.

The effective synthesis of $\mathbf{1 0 b}$ was thus required to prepare the pool of 18b-RNA conjugates. We explored a single-reaction approach to synthesize $\mathbf{1 0 b}$ by reacting bromoacetyl bromide $(\mathrm{BrAcBr})$ with a molar excess of cystamine (7b). TLC and NMR analyses indicated that the reaction products were too complicated to resolve and gave no evidence for the production of $\mathbf{1 0 b}$. We reasoned that, in the presence of a molar excess of $\mathbf{7 b}$, nucleophilic substitution reactions between the two amino groups in $\mathbf{7 b}$ and the bromine in both the carbonyl carbon and the less reactive methylene carbon of $\mathrm{BrAcBr}$ might have resulted in polymerization products that we did not further characterize. Therefore, we modified the synthesis strategy for $10 \mathrm{~b}$ by utilizing $N$-tert-butoxycarbonyl (Boc) to protect one of the amino groups in $\mathbf{7 b}$ to produce $\mathbf{8 b}(39 \%))^{34}$ This was followed by the acylation of $\mathbf{8 b}$ in the presence of a molar excess of $\mathrm{BrAcBr}$ and subsequent TFA deprotection to obtain $10 \mathrm{~b}(40 \%$; Scheme $3 \mathrm{~A})$. The successful synthesis of $\mathbf{1 0 b}$ ultimately led to the in vitro selection of the TW17 ribozyme. $^{18}$

In our attempt to characterize the substrate specificity of the ribozyme catalysis to determine the chemical reaction mechanism accelerated by the TW17 ribozyme, we realized that the organic synthesis of $\mathbf{1 8 b}$ was imperative to achieve this aim. The successful synthesis of $\mathbf{1 8 b}$ (Scheme 4) was attained in the following manner. Biotin (11) was converted to 14 using a previously published method..$^{35}$ Compound $\mathbf{1 4}$ was then reacted with $8 \mathbf{b}$ to acquire $15 \mathbf{b}(81.5 \%)$. The TFA deprotection of 15b produced 16b, which was then subjected to amidation with 17 to produce the desired $\mathbf{1 8 b}(20.6 \%)$. The structure of $\mathbf{1 8 b}$ was 


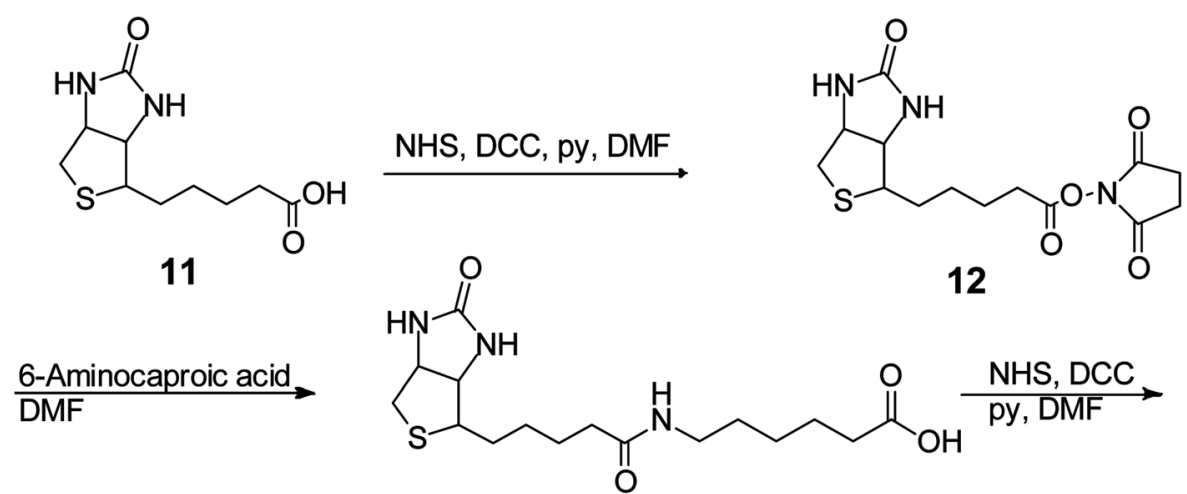<smiles>CCON(C)C(=O)CCCCCNC(=O)CCCCCC1SCC2NC(=O)NC21</smiles><smiles>[R]CCCNC(=O)CCCCCNC(=O)CCCCC1SCC2NC(=O)NC21</smiles><smiles>[R]CCNC(=O)CCCCCNC(=O)CCCCC1SCC2NC(=O)NC21</smiles><smiles>[R]CCNC(=O)CCCCCCNC(=O)CCCCC1SCC2NC(=O)NC21</smiles>

Scheme 4 Synthesis of the substrates utilized in studying the $\mathrm{Zn}^{2+}$-dependent hydrolytic mechanism of the TW17 ribozyme.

confirmed by ${ }^{1} \mathrm{H}$ and ${ }^{13} \mathrm{C}$ NMR spectroscopy. Moreover, $18 \mathrm{~b}$ was able to be effectively linked to the TW17 ribozyme and to support the expected ribozyme catalysis. ${ }^{18}$

However, as indicated previously, ${ }^{18}$ the presence of multiple functional groups in $\mathbf{1 8 b}$, the phosphorothiolate thiolester bond between $18 \mathrm{~b}$ and the TW17 ribozyme, and the numerous phosphodiester linkages in the TW17 ribozyme hampered the straightforward determination of the type of chemical reactions catalyzed by the TW17 ribozyme. Consequently, we performed systematic TW17 ribozyme catalysis studies in order to rule out reactions not catalyzed by the TW17 ribozyme. We utilized 18a, a structural analog of $\mathbf{1 8 b}$ lacking the internal disulfide bond, to demonstrate that the TW17 ribozyme was not a disulfide reductase RNA. The synthesis of $\mathbf{1 8 a}$ was very similar to that of $\mathbf{1 8 b}$, except that the reactant $\mathbf{8 b}$ was replaced by $\mathbf{8 a}$ (Schemes 3 and 4). In addition, the intermediate 16a in the 18a synthesis process was obtained by following reported methods. ${ }^{35}$ The amidation reaction between $16 a$ and 17 resulted in the synthesis of $18 \mathrm{a}(58.5 \%)$. The acquired $18 \mathrm{a}$ was later coupled to the TW17 ribozyme, and the resulting 18a-ribozyme conjugate exhibited catalytic activity identical to that of the TW17 ribozyme appended with $\mathbf{1 8 b} .^{18}$ Therefore, we ruled out the 
possibility that the TW17 ribozyme functions as a disulfide reductase RNA.

We synthesized 10a to determine whether the TW17 ribozyme could function as an amidase RNA by hydrolyzing the second amide bond (relative to the phosphorothiolate ester bond) in the 18-TW17 ribozyme conjugate. The synthesis of 10a was straightforward and analogous to the synthesis scheme for 10b except that $7 \mathbf{a}$ was substituted for $\mathbf{7 b}$ (Scheme 3A). The yield from $\mathbf{8 a}$ to 10a was $35.5 \%$. Compound 10a was again effectively conjugated to the TW17 ribozyme to give the 10a-TW17 ribozyme conjugate, which showed a significantly different migration from that of the TW17 ribozyme catalysis product in high-resolution urea-PAGE. ${ }^{18}$ This finding excluded the possibility that the ribozyme was an amidase RNA that hydrolyzed the indicated amide linkage. Finally, the additional chemical and biochemical characterization of TW17 ribozyme catalysis confirmed the conclusion that the ribozyme was a $\mathrm{Zn}^{2+}$-dependent phosphorothiolate thiolesterase RNA (Scheme 1). ${ }^{18}$ Because 18a was synthesized with a higher yield than that of $\mathbf{1 8 b}$, we chose $\mathbf{1 8 a}$ as the substrate to be coupled to the TW17 ribozyme and to yield the 18a-ribozyme conjugate for all the future kinetic studies of TW17 ribozyme catalysis. The decision was further supported by the fact that, as previously described, the TW17 ribozyme demonstrated almost identical catalytic activity when covalently linking the ribozyme to either 18a or $\mathbf{1 8 b} .^{18}$

\section{Characteristics of metal cofactors in TW17 ribozyme catalysis}

Our previous study revealed that TW17 ribozyme catalysis was $\mathrm{Zn}^{2+}$-dependent and was more efficient in the presence of both $\mathrm{Zn}^{2+}$ and $\mathrm{Mg}^{2+} .^{18}$ To gain insights into the intricate roles that divalent metal cations play in TW17 ribozyme activity, we analyzed ribozyme catalysis reactions in the presence of various concentrations of $\mathrm{Zn}^{2+}, \mathrm{Mg}^{2+}$, or $\left[\mathrm{Co}\left(\mathrm{NH}_{3}\right)_{6}\right]^{3+}$. We were especially interested in obtaining information about the roles that $\mathrm{Zn}^{2+}$, inner-sphere $\mathrm{Mg}^{2+}$, and outer-sphere $\mathrm{Mg}^{2+}$ might play in sustaining optimal TW17 ribozyme catalysis. Moreover, we exploited classical Hill plot analyses to reveal correlations between the zinc concentrations and TW17 ribozyme catalysis. Early ribozyme studies utilized a similar approach of using the Hill equation to characterize discrete and independent sites for ion binding in ribozymes, and, typically, the data fitted to the Hill equation moderately well. ${ }^{36,37}$ Subsequent studies, however, indicated that the parameters from Hill analyses of metal ionRNA titrations in earlier ribozyme research were derived from a simplified ligand-binding model of the metal ion-RNA association, which poorly represented the actual environment of the ribozyme..$^{12,13,38}$ The problem of inappropriately applying the Hill equation to estimate the number of ligand-binding sites in biomacromolecules has also been explicated. ${ }^{39}$ We thus did not attempt to determine discrete zinc binding sites in the TW17 ribozyme under predefined ribozyme catalysis conditions. Instead, our Hill analyses on data from the zinc titration studies of TW17 ribozyme catalysis were performed to correlate the catalytic activity with the properties of the specifically associated $\mathrm{Zn}^{2+}$ and $\mathrm{Mg}^{2+}$ in the ion atmosphere surrounding the TW17 ribozyme.
We first measured $k_{\text {obs }}$ values of TW17 ribozyme catalysis as a function of $\mathrm{Zn}^{2+}$ concentrations in the presence of a constant $\mathrm{Mg}^{2+}$ value of $100 \mathrm{mM}$ in order to better understand the indispensable role of $\mathrm{Zn}^{2+}$ in the ion atmosphere of the ribozyme. A concentration of $100 \mathrm{mM} \mathrm{Mg}^{2+}$ was implemented because this was the $\mathrm{Mg}^{2+}$ concentration used in the standard condition of our original TW17 ribozyme study. ${ }^{18}$ The TW17 ribozyme showed insignificant catalytic activity in $\mathrm{Zn}^{2+}$ concentrations below $125 \mu \mathrm{M}$, but exhibited a steady increase of $k_{\text {obs }}$ when the $\mathrm{Zn}^{2+}$ concentrations were increased incrementally above 125 $\mu \mathrm{M}$ (Fig. 1A). Hill analyses of $k_{\text {obs }}$ from each $\mathrm{Zn}^{2+}$ concentration indicated that the ribozyme had a Hill coefficient $(h)$ of 3.9, a dissociation constant $\left(K_{\mathrm{d}}\right)$ of $520 \pm 4 \mu \mathrm{M}$, and a $k_{\mathrm{obs}, \max }$ of 6.7 $\times 10^{-2} \pm 0.1 \times 10^{-2} \mathrm{~min}^{-1}$ (Table 1 ). The results suggested that each TW17 ribozyme molecule required a minimum of 3.92 equivalences of $\mathrm{Zn}^{2+}$ specifically associated in the $\left[\mathrm{Mg}^{2+}\right](=100$ $\mathrm{mM}$ )-containing ion atmosphere of the ribozyme for proper catalysis. The large average $K_{\mathrm{d}}$ of $520 \mu \mathrm{M}$ likely reflects the dynamic nature of specifically associated $\mathrm{Zn}^{2+}$ in the ion atmosphere of the TW17 ribozyme. In addition, the presence of $\mathrm{Zn}^{2+}$ had a positive and cooperative effect on TW17 ribozyme catalysis. Moreover, the $k_{\mathrm{obs}}$ of the ribozyme more than doubled when the $\mathrm{Zn}^{2+}$ concentrations were increased from the $0.5 \mathrm{mM}$ used in standard ribozyme catalysis to $1.25 \mathrm{mM}$. Since the deviation from the maximum $k_{\mathrm{obs}}\left(k_{\mathrm{obs}, \max }=6.7 \times 10^{-2} \pm 0.1 \times\right.$ $10^{-2} \mathrm{~min}^{-1}$ in Table 1) was not substantial, however, we maintained a $\mathrm{Zn}^{2+}$ concentration of $0.5 \mathrm{mM}$ in all subsequent metal titrations in order to compare the current results with our previously published TW17 ribozyme catalysis findings. ${ }^{18}$

We also exploited metal titration studies to determine the contribution to optimal TW17 ribozyme catalysis by the $\mathrm{Mg}^{2+}$ specifically associated with the ribozyme in the ion atmosphere. We reasoned that, by measuring the $k_{\mathrm{obs}}$ of ribozyme catalysis as a function of $\mathrm{Zn}^{2+}$ concentrations in the absence of $\mathrm{Mg}^{2+}$, we could unveil the requirements of not only $\mathrm{Zn}^{2+}$ but also $\mathrm{Mg}^{2+}$ for optimal TW17 ribozyme activity. As before, the TW17 ribozyme had no catalytic activity at $\mathrm{Zn}^{2+}$ concentrations below $125 \mu \mathrm{M}$; above $125 \mu \mathrm{M}$, the $k_{\text {obs }}$ increased steadily and directly with a rise in $\mathrm{Zn}^{2+}$ concentration (Fig. 1B). For example, $0.5 \mathrm{mM} \mathrm{Zn}^{2+}$ itself was sufficient for TW17 ribozyme catalysis $\left(k_{\mathrm{obs}, 0.5 \mathrm{mM} \mathrm{z} n^{2+}}=\right.$ $0.005 \mathrm{~min}^{-1}$; Fig. $\left.\mathrm{S} 1 \dagger\right)$. The results again confirmed the obligatory presence of $\mathrm{Zn}^{2+}$ for TW17 ribozyme catalysis. Hill analyses of the $k_{\mathrm{obs}}$ from each $\mathrm{Zn}^{2+}$ concentration produced values for $h$ of $4.3, K_{\mathrm{d}}$ of $580 \pm 20 \mathrm{mM}$ and a $k_{\text {obs,max }}$ of $1.8 \times 10^{-2} \pm 0.1$ $\times 10^{-2} \mathrm{~min}^{-1}$ (Table 1 ).

The results obtained from $\mathrm{Zn}^{2+}$ titration in the presence and absence of $100 \mathrm{mM} \mathrm{Mg}{ }^{2+}$ (Fig. 1A, B, and Table 1) clearly indicated that the specifically associated $\mathrm{Zn}^{2+}$ in the ion atmosphere of the TW17 ribozyme had similar values of $h$ and $K_{\mathrm{d}}$ in the absence and presence of $\mathrm{Mg}^{2+}$. The value of $k_{\mathrm{obs} \text {,max }}$, however, showed over a threefold decrease (from $6.7 \times 10^{-2} \pm 0.1 \times$ $10^{-2} \mathrm{~min}^{-1}$ to $1.8 \times 10^{-2} \pm 0.1 \times 10^{-2} \mathrm{~min}^{-1}$ ) when $\mathrm{Mg}^{2+}$ was removed from TW17 ribozyme catalysis. These results strongly support the previous findings ${ }^{18}$ that $\mathrm{Mg}^{2+}$ is not absolutely required for the catalytic activity of the TW17 ribozyme but is essential for optimal ribozyme catalysis. 
(A)

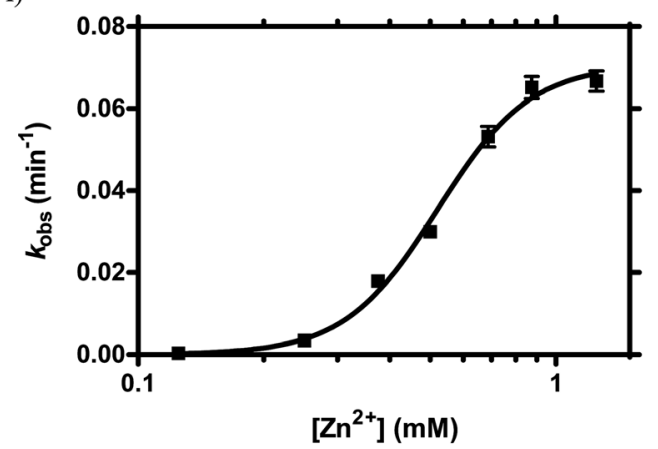

(C)

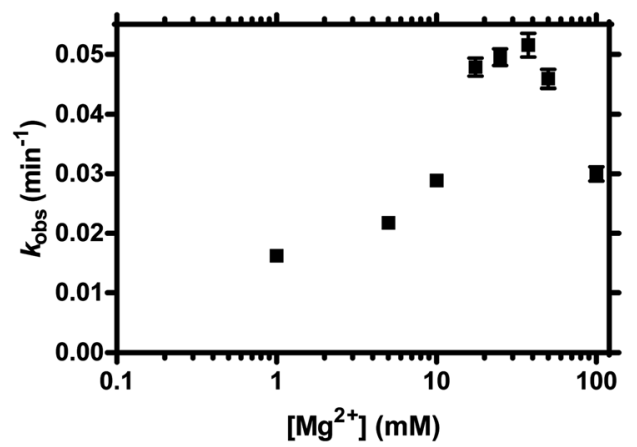

(B)

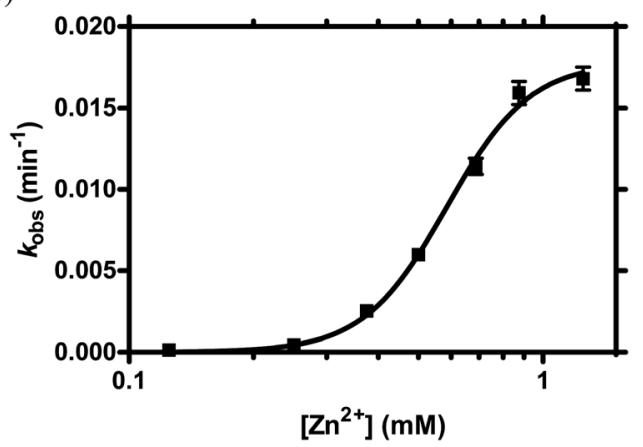

(D)

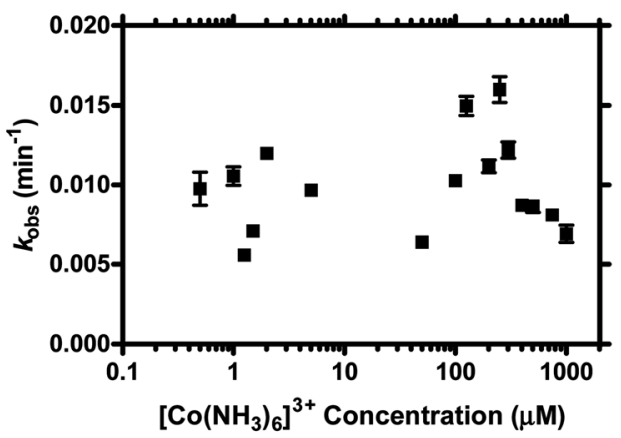

Fig. 1 Metal titration in TW17 ribozyme catalysis to demonstrate the absolute requirement for $\mathrm{Zn}^{2+}$ and the critical role of inner- and outersphere $\mathrm{Mg}^{2+}$ association for optimal TW17 ribozyme catalysis. (A) The $\mathrm{Zn}^{2+}$-associated ion atmosphere surrounding the TW17 ribozyme was titrated by measuring the $k_{\text {obs }}$ of ribozyme catalysis under various $\mathrm{Zn}^{2+}$ concentrations $(0.125-1.25 \mathrm{mM})$ and with a constant $\left[\mathrm{Mg} \mathrm{g}^{2+}\right]=100 \mathrm{mM}$. (B) $\mathrm{Zn}^{2+}$ in the ion atmosphere encompassing the TW17 ribozyme was titrated by measuring the $k_{\text {obs }}$ of ribozyme catalysis under varying $Z \mathrm{n}^{2+}$ concentrations $(0.125-1.25 \mathrm{mM})$ in the absence of $\mathrm{Mg}^{2+}$. Each kinetic study of TW17 ribozyme catalysis was performed according to the standard reaction condition (see Experimental section) except that the standard concentrations of divalent metal ions were replaced by the specified concentrations of each divalent metal ion as stated above. Data from (A) and (B) were non-linearly fitted into the Hill equation (see Experimental section) to obtain the Hill coefficient $(h)$, maximum $k_{\text {obs }}\left(k_{\text {obs,max }}\right)$, and average dissociation constant $\left(K_{d}\right)$. (C) The association of $M g^{2+}$ in the ion atmosphere of the TW17 ribozyme was studied by determining the $k_{\text {obs }}$ of ribozyme catalysis under varying $\mathrm{Mg}^{2+}$ concentrations $(1-100 \mathrm{mM})$ and with a constant $\left[\mathrm{Zn}^{2+}\right]$ of $0.5 \mathrm{mM}$. (D) Effects of $\left[\mathrm{Co}\left(\mathrm{NH}_{3}\right)_{6}\right]^{3+}$ concentrations in TW17 ribozyme catalysis were determined by measuring the $k_{\mathrm{obs}}$ of the hydrolytic reaction in the presence of $0.5 \mathrm{mM} \mathrm{Zn}^{2+}$. Each data point was the mean value of the determined $k_{\mathrm{obs}}$ in three titration experiments, with the standard deviation represented by an up and down bar. Standard deviation bars for some data points are too small to be visible in the graph.

Table 1 Dissociation constants $\left(K_{\mathrm{d}}\right)$, maximal rate constants $\left(k_{\mathrm{obs}, \mathrm{max}}\right)$, and Hill coefficients $(h)$ from metal titration studies of TW17 ribozyme catalysis

\begin{tabular}{llll}
\hline Titrated metal & $K_{\mathrm{d}}(\mu \mathrm{M})$ & $k_{\text {obs,max }}\left(\mathrm{min}^{-1}\right)$ & $h$ \\
\hline $\mathrm{Zn}(\mathrm{II})^{a}$ & $520 \pm 4$ & $6.7 \times 10^{-2} \pm 0.1 \times 10^{-2}$ & 3.9 \\
$\mathrm{Zn}(\mathrm{II})^{b}$ & $580 \pm 20$ & $1.8 \times 10^{-2} \pm 0.1 \times 10^{-2}$ & 4.3
\end{tabular}

${ }^{a}$ In the presence of $100 \mathrm{mM} \mathrm{Mg}^{2+} .{ }^{b}$ In the absence of $\mathrm{Mg}^{2+}$.

We further characterized the specific association of $\mathrm{Mg}^{2+}$ in the ion atmosphere surrounding the TW17 ribozyme by measuring the $k_{\mathrm{obs}}$ of TW17 ribozyme catalysis as a function of varying $\mathrm{Mg}^{2+}$ concentrations in the presence of a constant concentration of $0.5 \mathrm{mM} \mathrm{Zn^{2+ }}$. It is known that both innersphere and outer-sphere $\mathrm{Mg}^{2+}$ have functional roles in ribozyme catalysis. ${ }^{4,5}$ In the current study, the addition of $0.5 \mathrm{mM}$ $\mathrm{Zn}^{2+}$ to the $\mathrm{Mg}^{2+}$ titration was crucial to understand the dedicated roles of $\mathrm{Mg}^{2+}$ in TW17 ribozyme catalysis because we had previously shown that $\mathrm{Mg}^{2+}$ alone cannot support ribozyme catalysis. ${ }^{18}$ The TW17 ribozyme displayed catalytic activity due to the $\mathrm{Zn}^{2+}$ background only when the $\mathrm{Mg}^{2+}$ concentration was below $1 \mathrm{mM}$ but displayed a continuous increase of $k_{\text {obs }}$ when the $\mathrm{Mg}^{2+}$ concentration was greater than $1 \mathrm{mM}$ and up to $37.5 \mathrm{mM}$, as the concentration where the TW17 ribozyme attained the maximum catalysis $\left(k_{\mathrm{obs}}=0.052 \mathrm{~min}^{-1}\right.$; Fig. 1C). The results were consistent with the conclusion that $\mathrm{Mg}^{2+}$ is required for optimal TW17 ribozyme catalysis. The activity of the ribozyme, however, steadily declined when $\mathrm{Mg}^{2+}$ concentrations were increased beyond $37.5 \mathrm{mM}$. For example, the $k_{\mathrm{obs}}$ of the TW17 ribozyme decreased from $0.046 \mathrm{~min}^{-1}$ to $0.030 \mathrm{~min}^{-1}$ when the $\mathrm{Mg}^{2+}$ concentration was increased from $50 \mathrm{mM}$ to $100 \mathrm{mM}$, which is the $\mathrm{Mg}^{2+}$ concentration used in standard ribozyme catalysis. ${ }^{18}$ The decrease in activity was likely the result of the excess $\mathrm{Mg}^{2+}$ disturbing the TW17 ribozyme structure and impeding effective ribozyme catalysis. We decided to obtain kinetic data using the suboptimal concentration of $100 \mathrm{mM} \mathrm{Mg}^{2+}$ in TW17 ribozyme catalysis as it still bestowed $65 \%$ of the normalized maximum $k_{\text {obs }}$ and allowed us to directly compare the results to those of previous ribozyme studies. ${ }^{18}$ 
We also performed $\left[\mathrm{Co}\left(\mathrm{NH}_{3}\right)_{6}\right]^{3+}$ titration of the reaction catalyzed by the TW17 ribozyme to differentiate the relative importance of inner- and outer-sphere $\mathrm{Mg}^{2+}$ in sustaining optimal ribozyme catalysis. In aqueous solutions, $\mathrm{Mg}^{2+}$ can coordinate with six water molecules to form $\left[\mathrm{Mg}\left(\mathrm{H}_{2} \mathrm{O}\right)_{6}\right]^{2+}$, in which the hexahydrated $\mathrm{Mg}^{2+}$ complex can electrostatically attract appropriate functional groups in RNA by outer-sphere coordination. ${ }^{4}$ Exchange-inert $\left[\mathrm{Co}\left(\mathrm{NH}_{3}\right)_{6}\right]^{3+}$ is very similar in size to $\left[\mathrm{Mg}\left(\mathrm{H}_{2} \mathrm{O}\right)_{6}\right]^{2+}$ and has been shown to serve as a substitute for $\left[\mathrm{Mg}\left(\mathrm{H}_{2} \mathrm{O}\right)_{6}\right]^{2+}$ for supporting ribozyme catalysis. ${ }^{4,5}$ Indeed, we observed a $\left[\mathrm{Co}\left(\mathrm{NH}_{3}\right)_{6}\right]^{3+}$-dependent increase of TW17 ribozyme activity when including $50 \mu \mathrm{M}\left[\mathrm{Co}\left(\mathrm{NH}_{3}\right)_{6}\right]^{3+}$ to the ribozyme catalysis reaction previously performed in the presence of only $0.5 \mathrm{mM}$ of $\mathrm{Zn}^{2+}$ (lanes 4 and 8 in Fig. S2 $\uparrow$ ). In addition, $\left[\mathrm{Co}\left(\mathrm{NH}_{3}\right)_{6}\right]^{3+}$ alone did not result in any detectable TW17 ribozyme catalytic activity, which was consistent with the results and suggested a secondary and structural role of $\mathrm{Mg}^{2+}$ in ribozyme catalysis. ${ }^{18}$ When acquiring the $k_{\mathrm{obs}}$ of TW17 ribozyme catalysis as a function of $\left[\mathrm{Co}\left(\mathrm{NH}_{3}\right)_{6}\right]^{3+}$ concentrations in the presence of a constant concentration of $0.5 \mathrm{mM} \mathrm{Zn}^{2+}$, we obtained values for $k_{\mathrm{obs}}$ that unexpectedly fluctuated between $0.006 \mathrm{~min}^{-1}$ and $0.016 \mathrm{~min}^{-1}$ for ribozyme catalysis when titrating $\left[\mathrm{Co}\left(\mathrm{NH}_{3}\right)_{6}\right]^{3+}$ from $0.5 \mu \mathrm{M}$ to $1000 \mu \mathrm{M}$ (Fig. 1D). Moreover, these values of $k_{\text {obs }}$ were all smaller than the $k_{\mathrm{obs} \text {,max }}$ value of $0.052 \mathrm{~min}^{-1}$ obtained from the $\mathrm{Mg}^{2+}$ titration of TW17 ribozyme catalysis (Fig. 1C), which indicates the insufficiency of the combination of $\left[\mathrm{Co}\left(\mathrm{NH}_{3}\right)_{6}\right]^{3+}$ and $\mathrm{Zn}^{2+}$ for appropriate TW17 ribozyme catalysis. Consequently, the results of the $\mathrm{Zn}^{2+}$-only titration (Fig. 1B), and also of the $\mathrm{Mg}^{2+}$ and $\left[\mathrm{Co}\left(\mathrm{NH}_{3}\right)_{6}\right]^{3+}$ titrations in the presence of $\left[\mathrm{Zn}^{2+}\right]=0.5 \mathrm{mM}$ (Fig. $1 \mathrm{C}$ and $\mathrm{D}$ ) indicated that both inner-sphere and outer-sphere $\mathrm{Mg}^{2+}$ are equally required for optimal TW17 ribozyme catalysis.

\section{TW17 ribozyme catalysis is facilitated in alkaline conditions}

Similar to protein enzymes for functional group transfer reactions, the catalytic mechanisms of ribozymes generally involve proton transfer in general acid-base catalysis to achieve a rate enhancement. ${ }^{7,8}$ Understanding the acid-base chemistry of ribozymes is essential to comprehending the intricate reaction mechanisms of ribozyme catalysis. Consequently, we performed TW17 ribozyme catalysis in varying $\mathrm{pH}$ conditions to evaluate the influence of $\mathrm{pH}$ on ribozyme catalysis and to shed light on the detailed catalysis mechanism of the ribozyme (Fig. 2). The TW17 ribozyme exhibited barely any detectable activity $\left(k_{\mathrm{obs}} \sim 0\right)$ when the $\mathrm{pH}$ of the reaction was below 6.5. The $k_{\mathrm{obs}}$ gradually increased as the $\mathrm{pH}$ of the reaction increased from 6.5 to 7.4 , at which point the TW17 ribozyme displayed a drastic increase in $k_{\text {obs. }}$. The TW17 ribozyme had a similar $k_{\text {obs }}$ at all pH levels between 7.5 and 8.0. The TW17 ribozyme, however, gave a significant fluctuation of the $k_{\text {obs }}$ values when the $\mathrm{pH}$ of the reaction mixture was higher than 8.0. Since an increase in the catalytic rates in alkaline conditions is one of the characteristics in the mechanism of general base catalysis, the $\mathrm{pH}$ titration data thus suggested that TW17 ribozyme catalysis could involve a general base. However, the current $\mathrm{pH}$ titration results deviate significantly from those typically observed with general base catalysis ${ }^{40}$ and prevented the

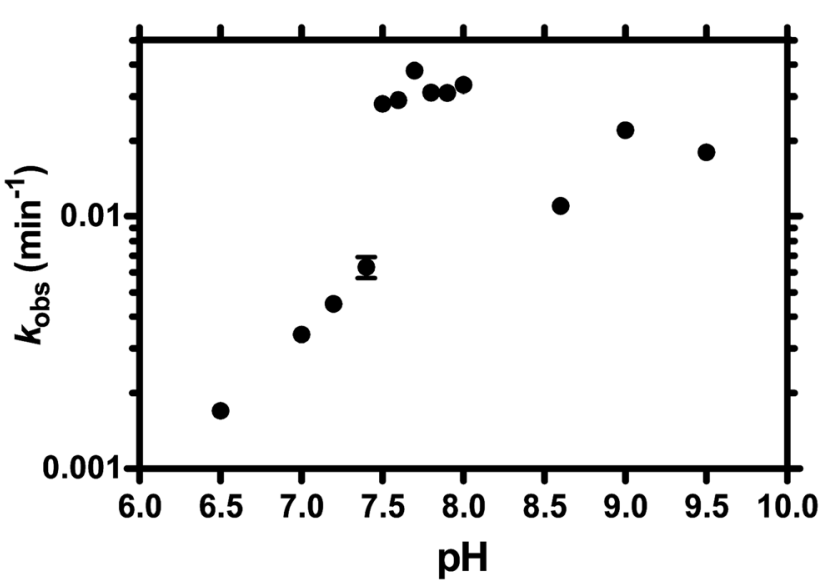

Fig. 2 Evidence for the requirement for alkaline conditions in TW17 ribozyme catalysis. Reactions were carried out under the conditions provided in the Experimental section. The values of $k_{\text {obs }}$ measured in the presence of buffer solutions with specific $\mathrm{pH}$ values were determined as before. Each data point was the mean value of analyses performed in triplicate, with the standard deviation represented by an up and down bar. The standard deviation bars for some data points are too small to be visible.

fitting of the $k_{\mathrm{obs}}$ data of TW17 ribozyme catalysis at each pH in order to acquire the values of $\mathrm{p} K_{\mathrm{a}}$ for a general base and the $k_{\text {obs,max }}$ in the presence of the general base. Nevertheless, the TW17 ribozyme unequivocally demonstrated the ability to accelerate catalysis in alkaline conditions.

\section{Additional base-pairings between substrate-bearing and catalytic RNA molecules in trans-acting TW17 ribozyme catalysis systems unable to enhance their binding affinities}

The metal titration studies (Fig. 1) provided critical information concerning the appropriate $\mathrm{Zn}^{2+}$ and $\mathrm{Mg}^{2+}$ concentrations for optimal TW17 ribozyme catalysis, and suggested a strategy to improve the catalysis of a previously reported trans-acting TW17 ribozyme system with $K_{\mathrm{M}}=1.77 \pm 1.20 \mu \mathrm{M}, k_{\text {cat }}=1.65 \pm$ $0.80 \mathrm{~min}^{-1}$, and $k_{\text {cat }} / K_{\mathrm{M}}=1.6 \times 10^{4} \pm 1.3 \times 10^{4} \mathrm{~s}^{-1} \mathrm{M}^{-1} .{ }^{18}$ The trans-acting TW17 ribozyme system consisted of the substratebearing $\mathrm{S}_{1-18}$ RNA (designated as TW17S-1 RNA in this study) and the catalysis-active TW17 $7_{22-87}$ ribozyme RNA (renamed as TW17C-1 RNA here), and exploited 6-8 base-pairings (bp) in the P1 region to form a complex between these two RNA molecules (Fig. S3†)..$^{18}$ We reasoned that the trans-acting TW17 ribozyme system might confer better catalytic efficiency in the presence of the appropriate $\mathrm{Zn}^{2+}$ and $\mathrm{Mg}^{2+}$ concentrations required under optimal reaction conditions. In addition, the catalytic efficiency of the trans-acting TW17 ribozyme system might be further improved if the affinity between the substrate-bearing RNA and the catalytic core RNA in the trans-acting system could be increased. We thus decided to first modify the RNA structures in order to increase both the substrate-catalyst RNA affinity and the catalytic efficiency in trans-acting TW17 ribozyme systems. Greater catalytic efficiency in a trans-acting TW17 ribozyme system with modified RNA structures could then result from amending the optimal $\mathrm{Zn}$-dependent reactions in the presence of appropriate $\mathrm{Zn}^{2+}$ and $\mathrm{Mg}^{2+}$ concentrations. 
New trans-acting TW17 ribozyme systems utilizing modified RNA structures were obtained by increasing the numbers of bp in the P1 helix through site-directed mutagenesis and sequence insertions in this region (Fig. S3†). The syntheses of the RNA molecules in the different trans-acting TW17 ribozyme systems are described in Tables $\mathrm{S} 1$ and $\mathrm{S} 2 . \dagger$ We initially expected that an incremental increase in the number of bp in the P1 helix would promote the binding of substrate-bearing RNA to catalysisactive RNA and eventually increase the catalytic efficiencies in the trans-acting TW17 ribozyme systems. However, analysis of Langmuir binding isotherms as described in Table $\mathrm{S} 3 \uparrow$ revealed that the additional $\mathrm{bp}$ in the $\mathrm{P} 1$ helix never translated to a higher binding affinity-namely, a lower $K_{\mathrm{d}}$ and a more negative $\Delta G_{\text {binding }}$-in the structure-modified trans-acting TW17 ribozyme systems (Table S4 $\dagger$ ). On the contrary, more bp actually decreased the substrate-catalyst RNA binding affinities in almost all of the studied trans-acting TW17 ribozyme systems (Table $\mathrm{S} 4 \dagger$ ). Thus, fine-tuning bp in the $\mathrm{P} 1$ region is not a legitimate approach to improving the catalytic efficiency in trans-acting TW17 ribozyme systems.

\section{GNRA tetraloop motifs essential to optimal trans- phosphorothiolate thiolesterase activity of the TW17 ribozyme}

The incoherent correlation between the number of bp in the P1 region and ribozyme catalysis of trans-acting TW17 ribozyme systems led us to further scrutinize the structure of the cis-acting TW17 ribozyme (Fig. S4 $\dagger)^{\mathbf{1 8}}$ and to evaluate the importance of a GAGA tetraloop (L1 in Fig. S4 $\dagger$ ) for capping the P1 helix in the RNA. The GAGA tetraloop was dissected in the original experiments involving the trans-acting TW17 ribozyme system (the TW17S-1 RNA + TW17C-1 RNA system) and was further disrupted in later experiments using the trans-acting systems for Langmuir isotherm analysis (Fig. S3†). The GAGA tetraloop belongs to a previously described family of GNRA tetraloops. ${ }^{19-21}$ Thus, the structure of the GAGA tetraloop might engage in a long-range interaction with a corresponding receptor RNA motif and might act to stabilize the tertiary structure of the TW17 ribozyme. This stabilization could be essential for optimal catalysis of the ribozyme. We therefore constructed two GAGA tetraloopcontaining trans-acting TW17 ribozyme systems (Fig. 3A and B) and evaluated whether the presence of the GAGA tetraloop improved the catalytic efficiency of the ribozyme.

With no requirement to further modify the structure of the TW17 ribozyme, except for dividing the cis-acting ribozyme into two RNA fragments, we first determined the optimal metal concentrations for TW17 ribozyme catalysis, because the previous experiments with the trans-acting TW17 ribozyme system yielded poor catalytic efficiency under the standard reaction condition of $\left[\mathrm{Zn}^{2+}\right]=0.5 \mathrm{mM}$ and $\left[\mathrm{Mg}^{2+}\right]=100 \mathrm{mM} .^{18}$ Metal titration studies had already indicated that the cis-acting TW17 ribozyme performed better in the presence of either $\left[\mathrm{Zn}^{2+}\right]=1.25 \mathrm{mM}$ or $\left[\mathrm{Mg}^{2+}\right]=37.5 \mathrm{mM}$ (Fig. 1). Since the cisacting TW17 ribozyme was easier to synthesize and had demonstrated more efficient catalysis than the original transacting TW17 ribozyme system, we again exploited the cis- acting RNA to acquire appropriate metal concentration combinations for improved TW17 ribozyme catalysis. We studied TW17 ribozyme catalysis in the presence of the following three different metal concentration combinations: (1) $\left[\mathrm{Zn}^{2+}\right]=$ $1.25 \mathrm{mM}$ and $\left[\mathrm{Mg}^{2+}\right]=100 \mathrm{mM} ;(2)\left[\mathrm{Zn}^{2+}\right]=0.5 \mathrm{mM}$ and $\left[\mathrm{Mg}^{2+}\right]$ $=37.5 \mathrm{mM} ;(3)\left[\mathrm{Zn}^{2+}\right]=1.25 \mathrm{mM}$ and $\left[\mathrm{Mg}^{2+}\right]=37.5 \mathrm{mM}$. Fig. S5 $\dagger$ clearly shows that the TW17 ribozyme, in the presence of a $\mathrm{Zn}^{2+}$ concentration of $0.5 \mathrm{mM}$ and a $\mathrm{Mg}^{2+}$ concentration of $37.5 \mathrm{mM}$, produced the highest catalytic efficiency among the three by providing a pseudo first-order rate constant $k_{\text {obs }}$ of $0.041 \mathrm{~min}^{-1}$, which was 0.46 -fold higher than the $k_{\text {obs }}$ value of $0.028 \mathrm{~min}^{-1}$ previously obtained in the standard reaction of TW17 ribozyme catalysis. ${ }^{18}$ The $\mathrm{Zn}^{2+}$ concentration of $0.5 \mathrm{mM}$ and the $\mathrm{Mg}^{2+}$ concentration of $37.5 \mathrm{mM}$ resulted in optimal catalysis of the TW17 ribozyme and were thus used in subsequent kinetic studies of the trans-acting TW17 ribozyme systems.

Time-course studies of TW17 ribozyme catalysis by the GAGA tetraloop-containing trans-acting systems (Fig. 3A and B) again confirmed that TW17 ribozyme catalysis in the presence of $\left[\mathrm{Zn}^{2+}\right]=0.5 \mathrm{mM}$ and $\left[\mathrm{Mg}^{2+}\right]=37.5 \mathrm{mM}$ was more efficient than when performed under the standard reaction condition (Fig. 3C and S6 $\dagger$ ). Additionally, the trans-acting TW17S $_{1-29}$ RNATW17C-1 RNA system unexpectedly demonstrated more efficient catalysis than the TW17 ${ }_{1-29}$ RNA-TW17C ${ }_{30-87}$ RNA system in all of the reaction conditions studied here. We initially assumed that the $5^{\prime}$ terminal segment in the TW17C-1 RNA might base-pair with the P1 helix in the TW17S ${ }_{1-29}$ RNA to destabilize the GAGA motif, leading to impaired TW17 ribozyme catalysis. The results shown in Fig. $3 \mathrm{C}$ and $\mathrm{S} 6 \uparrow$ thus suggest that destabilization of the secondary structure of the P1 helix might be required for optimal TW17 ribozyme catalysis. As the transacting $\mathrm{TW}_{17 \mathrm{~S}_{1-29}}$ RNA-TW17C-1 RNA system in the presence of the $\mathrm{Zn}^{2+}$ concentration of $0.5 \mathrm{mM}$ and the $\mathrm{Mg}^{2+}$ concentration of $37.5 \mathrm{mM}$ provided the largest initial velocity $\left(v_{\mathrm{i}}\right)$ of 0.2 $\mathrm{nM} \min ^{-1}$ and a 4 day yield of $33 \%$ (Fig. 3C), we decided to use these conditions in further studies of the multiple turnover catalysis.

The multiple substrate turnover capacity of the trans-acting TW17S $_{1-29}$ RNA-TW17C-1 ribozyme system was determined by measuring the $v_{\mathrm{i}}$ of the trans-acting TW17 ribozyme catalysis system under varied concentrations of the substrate-RNA (18aTW17S $_{1-29}$ RNA; 300-900 nM), a constant ribozyme (the TW17C1 ribozyme) concentration ( $30 \mathrm{nM})$, and constant substrate excess. Initial velocity $\left(v_{\mathrm{i}}\right)$ versus substrate concentration $([S])$ of the 18a-TW17S ${ }_{1-29}$ RNA were plotted (Fig. 3D) but did not provide reasonable values for the essential kinetic parameters, including for $K_{\mathrm{M}}$ and $k_{\text {cat }}$ for the in trans TW17 ribozyme catalysis system. Specifically, when performing nonlinear curve fitting of the data to the Michaelis-Menten equation, we obtained very large $K_{\mathrm{M}}$ and $k_{\text {cat }}$ values, with their standard errors even larger (results not shown). The acquisition of unrealistic values of $K_{\mathrm{M}}$ and $k_{\text {cat }}$ could have been predicted from Fig. 3D, which clearly indicates that the range of substrate concentrations utilized was not broad enough to accurately determine the kinetic constants for the in trans TW17 ribozyme catalysis system in this study. Nevertheless, the trans-acting TW17S $_{1-29}$ 
(A)

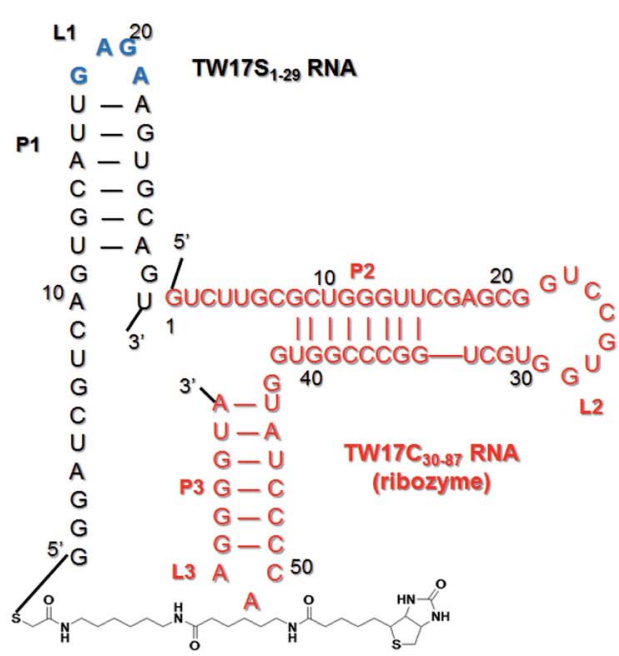

(C)

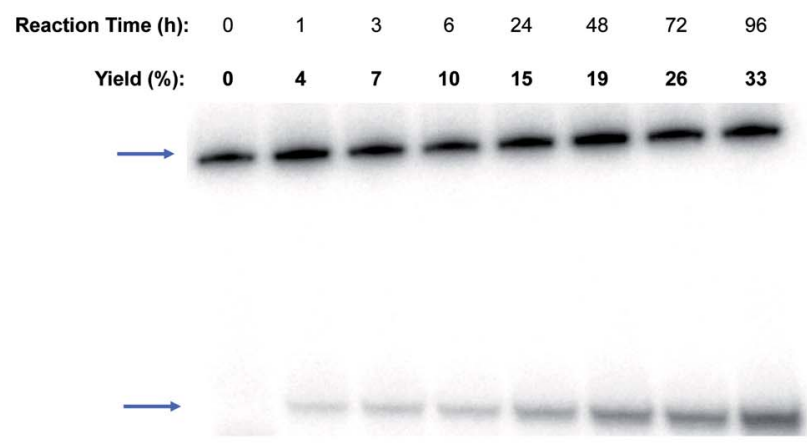

(B)

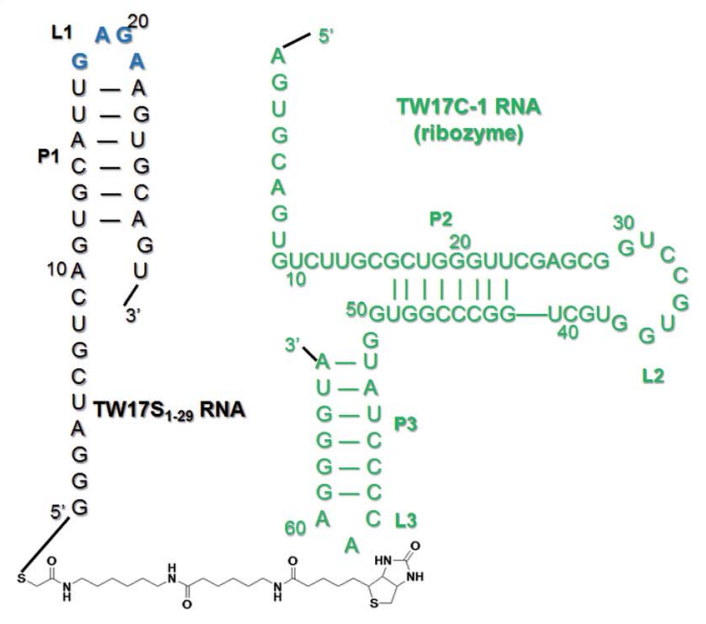

(D)

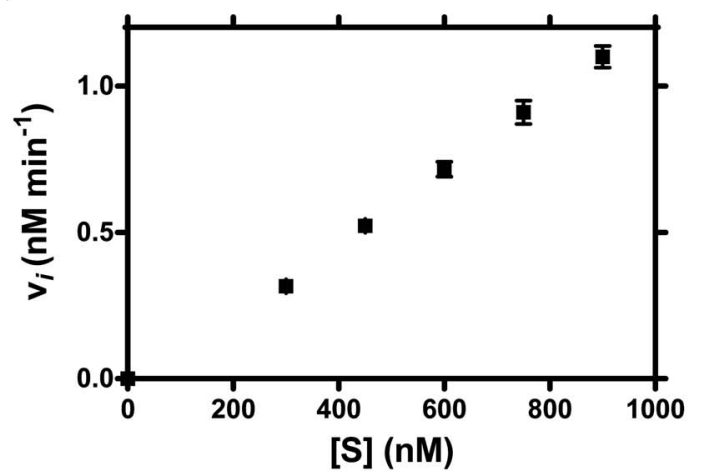

Fig. 3 Secondary structures of two GAGA tetraloop-containing trans-acting TW17 ribozyme systems and multiple substrate turnover kinetics of one of the GAGA tetraloop-containing trans-acting TW17 ribozyme systems. (A) The trans-acting ribozyme system consisted of the TW175 $1-29$ RNA (highlighted in black) and TW17C $30-87$ RNA (highlighted in red). (B) In the trans-acting TW17S $1-29$ RNA-TW17C-1 RNA system, the TW17C-1 RNA (highlighted in green) was substituted for the TW17S $30-87$ RNA used in (A). The GAGA tetraloop is highlighted in blue within the structure of the TW17S $_{1-29}$ RNA in both (A) and (B). In addition, the substrate 18a is covalently linked to the $5^{\prime}$ end of the TW17S $1-29$ RNA. (C) Multiple substrate turnover reactions of the trans-acting TW17S ${ }_{1-29}$ RNA-TW17C-1 system in the presence of the $\mathrm{Zn}^{2+}$ concentration of $0.5 \mathrm{mM}$ and $\mathrm{Mg}^{2+}$ concentration of $37.5 \mathrm{mM}$ were analyzed by SAv gel-shift assay in 20\% urea-PAGE. The catalysis in the multiple substrate turnover reactions was measured by including $300 \mathrm{nM}$ of the ${ }^{32}$ P-labeled 18a-TW17S $1-29$ RNA and $30 \mathrm{nM}$ of the TW17C-1 RNA in the reactions. The image was acquired using an Amersham Typhoon Phosphorlmager system and was quantified by ImageQuant software. The top blue arrow in the image represents the location of the SAv-retarded ${ }^{32} \mathrm{P}$-labeled $18 \mathrm{a}-\mathrm{TW}_{17 \mathrm{~S}_{1-29}}$ RNA conjugate; the bottom blue arrow indicates the migration of the ${ }^{32} \mathrm{P}$-labeled TW17 ribozyme-catalyzed reaction product. The initial velocity $\left(v_{\mathrm{i}}\right)$ was acquired by measuring the slope of the time-course curve from 0 to $1 \mathrm{~h}$ in

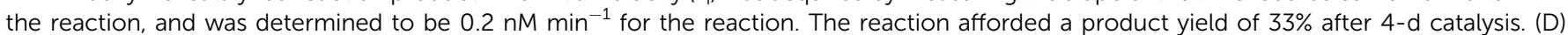
Multiple substrate turnover in the trans-acting TW17S ${ }_{1-29}$ RNA-TW17C-1 system was studied in the presence of a constant $30 \mathrm{nM}$ of the catalytic TW17C-1 ribozyme and an excess of the ${ }^{32}$ P-labeled $18 \mathrm{a}-\mathrm{S}_{1-29}$ RNA conjugate concentrations, ranging from 300 to $900 \mathrm{nM}$. Initial velocity data for each $18 \mathrm{a}-\mathrm{S}_{1-29}$ RNA conjugate concentration were acquired by measuring the slope of the time-course curve within the first 30 min of the reaction. Each data point in the figure is the average of two separate measurements.

RNA-TW17C-1 ribozyme system provided values of $v_{\mathrm{i}}$ and product yields (Fig. 3 and $56 \dagger$ ) significantly superior to those acquired from the original in trans TW17 ribozyme catalysis

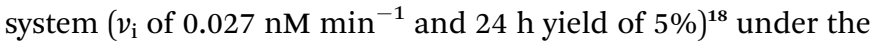
same concentrations of substrate and catalyst RNA molecules. This finding clearly demonstrates the requirement for the GAGA tetraloop in the TW17 ribozyme for optimal catalysis and provides essential information for designing additional catalysis-efficient multiple substrate turnover trans-acting systems for the ribozyme.

\section{Discussion}

We successfully synthesized and exploited $\mathbf{6}$ and $\mathbf{1 8 b}$ to select the TW17 ribozyme from an artificial RNA pool (Schemes 2-4). In addition, we meticulously synthesized 10a, 10b, and 18a because these compounds were essential for characterizing the substrate specificity of the TW17 ribozyme (Schemes 3 and 4). The effective synthesis of $\mathbf{6}$ was significant because the compound provided the critical molecular handle to link small substrate molecules, including 10 and 18, to the TW17 
ribozyme. We developed an improved strategy to synthesize $\mathbf{6}$ from 1 with an overall yield of $46 \%$ by avoiding the use of the troubling trialkyl phosphate solvent, which complicates the reaction with thiophosphoryl chloride and gives rise to undesirable oxygen/sulfur exchange products. ${ }^{30}$ The successful highyield synthesis of 6 provided a crucial impetus for the discovery of the TW17 ribozyme in addition to a straightforward approach to specifically modify RNA at the $5^{\prime}$ termini.

The synthesis of 18a was also important in this study as the structure of $\mathbf{1 8 a}$ differs from that of $\mathbf{1 8 b}$-the substrate used in the in vitro selection of the TW17 ribozyme-by only a disulfide bond not specifically cleaved by ribozyme catalysis. ${ }^{18}$ The current study demonstrated that the synthesis of 18a provides a much higher yield (54.9\% from 14 to $18 a$ ) than the synthesis of $18 b$ (16.8\% from 14 to $18 b$ ), while both compounds afforded the TW17 ribozyme conjugates with identical catalytic activity. Ready access to 18a provided a key advantage when synthesizing the TW17 ribozyme-18a conjugate for studying the kinetics of ribozyme catalysis and for understanding the intricate roles of divalent metal ions and tertiary interactions in ribozyme catalysis.

We investigated the critical roles of $\mathrm{Zn}^{2+}$ and $\mathrm{Mg}^{2+}$ in TW17 ribozyme catalysis by performing metal titration during ribozyme kinetics to gain insights into the simultaneous interactions of $\mathrm{Zn}^{2+}$ and $\mathrm{Mg}^{2+}$ with the ribozyme in the ion atmosphere and to optimize the hydrolytic reaction (Table 1 ). The results from the $\mathrm{Zn}^{2+}$ titration of TW17 ribozyme catalysis in the presence of a constant concentration of $100 \mathrm{mM} \mathrm{Mg}^{2+}$ indicated that the ribozyme absolutely requires specifically associated $\mathrm{Zn}^{2+}$ ions in the ion atmosphere to accelerate phosphorothiolate thiolester hydrolysis (Fig. 1A, Scheme 1 and Table 1). The role of the specifically associated $\mathrm{Zn}^{2+}$ in the TW17 ribozyme can be inferred from several $\mathrm{Zn}$ protein enzyme studies. Hydrolytic reactions catalyzed by many modern zinc-dependent protein hydrolases require the catalytic involvement of zinc ions that are often bound to proteins through inner-sphere coordination. ${ }^{\mathbf{1 4 , 1 5 , 1 7 , 2 5}}$ Inner-sphere zinc in these proteins is commonly coordinated by thiolates in the side chains of cysteine residues. Moreover, NMR and XAS analyses of RNase P revealed that zinc ions employ inner-sphere coordination with one or more RNA ligands in the ribozyme. ${ }^{\mathbf{4 1}}$ The results of these studies support the idea that $\mathrm{Zn}^{2+}$ ions crucial to TW17 ribozyme catalysis could be specifically bound to the ribozyme by inner-sphere coordination in the ion atmosphere. Further, the sulfur moiety in GMPS could be one of the ligands that coordinate $\mathrm{Zn}^{2+}$ in the 18a-TW17 ribozyme conjugate. We could not determine the coordination numbers or the geometries of the $\mathrm{Zn}^{2+}$ cations specifically associated with the TW17 ribozyme. The flexible coordination number (between four and six) and geometry (tetrahedral, trigonal bipyramidal, square pyramidal, and octahedral) of $\mathrm{Zn}^{2+}$ in zinc-dependent protein metalloenzymes, however, suggest similar possibilities for $\mathrm{Zn}^{2+}$ in the TW17 ribozyme. ${ }^{\mathbf{1 4 , 1 5 , 1 7 , 2 5}}$ We believe that one of the essential $\mathrm{Zn}^{2+}$ ions in the TW17 ribozyme active site coordinates with the ribozyme by four-folded inner-sphere interactions and uses the phosphorothiolate sulfur as one of its ligands (vide infra). However, advanced structural studies of the TW17 ribozyme are required to elucidate the coordination spheres and geometries of the specifically bound $\mathrm{Zn}^{2+}$ in the ribozyme.

In addition to the indispensable role of $\mathrm{Zn}^{2+}$ in TW17 ribozyme catalysis, the ribozyme also requires the inner-sphere and outer-sphere $\mathrm{Mg}^{2+}$ in the ion atmosphere for optimal catalysis. Titration studies of systematically changing $\mathrm{Zn}^{2+}$ concentrations in the absence of $\mathrm{Mg}^{2+}$ and of varying $\mathrm{Mg}^{2+}$ concentrations in the presence of a constant concentration of $0.5 \mathrm{mM} \mathrm{Zn}^{2+}$ in TW17 ribozyme catalysis provided evidence that the ribozyme could prime its structure for optimal catalysis in the presence of $\mathrm{Mg}^{2+}$ (Fig. 1B, C and Table 1) in the ion atmosphere. The importance of specifically associated outer-sphere $\mathrm{Mg}^{2+}$ for maintaining the TW17 ribozyme structure for optimal ribozyme catalysis was indicated by our $\left[\mathrm{Co}\left(\mathrm{NH}_{3}\right)_{6}\right]^{3+}$ titration studies of ribozyme kinetics (Fig. 1D and $\mathrm{S} 2 \dagger$ ). We unequivocally demonstrated that the presence of $\left[\mathrm{Co}\left(\mathrm{NH}_{3}\right)_{6}\right]^{3+}$ enhanced the catalytic activity of the ribozyme (Fig. $\mathrm{S} 2 \dagger$ ). It is noted that a similar $k_{\mathrm{obs}}$ could be obtained when using $\left[\mathrm{Co}\left(\mathrm{NH}_{3}\right)_{6}\right]^{3+}$ concentrations nearly two orders of magnitude lower than that of $\mathrm{Mg}^{2+}$. This result is as expected because $\left[\mathrm{Co}\left(\mathrm{NH}_{3}\right)_{6}\right]^{3+}$ has a larger charge than $\mathrm{Mg}^{2+}$ and, therefore, a greater capacity to stabilize the ribozyme structure. ${ }^{41}$ Incrementally increasing the $\left[\mathrm{Co}\left(\mathrm{NH}_{3}\right)_{6}\right]^{3+}$ concentration in the presence of $0.5 \mathrm{mM} \mathrm{Zn}^{2+}$, however, never resulted in wild-type catalytic activity for the TW17 ribozyme $\left(k_{\text {obs }}=0.028 \mathrm{~min}^{-1}\right.$; Fig. 1D). These results argue against a catalytic role of outer-sphere $\mathrm{Mg}^{2+}$ in TW17 ribozyme catalysis and support the conclusion that the main function of the outersphere $\mathrm{Mg}^{2+}$ is to stabilize the ribozyme structure for effective catalysis. Alternatively, the importance of specifically associated inner-sphere $\mathrm{Mg}^{2+}$ in the ion atmosphere of the TW17 ribozyme was also supported by the $\left[\mathrm{Co}\left(\mathrm{NH}_{3}\right)_{6}\right]^{3+}$ titration study of ribozyme catalysis in the presence of a constant concentration of $0.5 \mathrm{mM} \mathrm{Zn}^{2+}$ (Fig. 1D and S2 $\dagger$ ). As discussed above, additions of any concentration of $\left[\mathrm{Co}\left(\mathrm{NH}_{3}\right)_{6}\right]^{3+}$ never restored the wild-type activity of TW17 ribozyme catalysis. Moreover, the results of TW17 ribozyme catalysis titrated by $\mathrm{Zn}^{2+}$ exclusively also revealed that $\mathrm{Zn}^{2+}$ alone could also not fully recover the wildtype activity of the ribozyme (Fig. 1B). Consequently, the TW17 ribozyme demands the presence of both inner-sphere and outer-sphere $\mathrm{Mg}^{2+}$ in the ion atmosphere to modulate the ribozyme structure and to attain optimal ribozyme catalysis.

Titration studies of TW17 ribozyme catalysis at various $\mathrm{pH}$ levels provide crucial evidence indicating a requirement for alkaline conditions in ribozyme catalysis (Fig. 2). It is possible that TW17 ribozyme catalysis follows a general base mechanism. The current $\mathrm{pH}$ titration study, however, did not provide conclusive evidence to support the presence of a general base and to determine the values of $\mathrm{p} K_{\mathrm{a}}$ and $k_{\mathrm{obs} \text {,max }}$ for the general base. Nevertheless, we currently favor the hypothesis that hydrated $\mathrm{Zn}^{2+}$ plays the role of a general base to coordinate with the TW17 ribozyme by inner-sphere interactions at the active site. Deprotonation of a coordinated water ligand in the hydrated $\mathrm{Zn}^{2+}$ is thus indispensable for it to assume the proposed role of a general base. However, since solvated $\mathrm{Zn}(\mathrm{aq})^{2+}$ has a $\mathrm{p} K_{\mathrm{a}}$ of $\sim 9,{ }^{42}$ it implies that less than $90 \%$ of $\mathrm{Zn}(\mathrm{aq})^{2+}$ will be deprotonated at the optimal $\mathrm{pH}$ for ribozyme catalysis (pH 7.5-8.0; Fig. 2). Consequently, for effective TW17 
ribozyme catalysis, the hydrated $\mathrm{Zn}^{2+}$ in the ribozyme must increase the acidity of a water ligand and decrease its $\mathrm{p} K_{\mathrm{a}}$ from 9. The feasibility of an increase in the acidity of the hydrated $\mathrm{Zn}^{2+}$ in the TW17 ribozyme is again supported by a previous study demonstrating the deprotonation process of a coordinated water ligand from $\mathrm{Zn}(\mathrm{MeOPS})(\mathrm{aq})$ to $\mathrm{Zn}(\mathrm{MeOPS})(\mathrm{OH})^{-} \cdot{ }^{43}$ Significantly, the obtained $\mathrm{p} K_{\mathrm{a}}$ for the deprotonation process of $\mathrm{Zn}(\mathrm{MeOPS})(\mathrm{aq})$ was $6.9 \pm 0.2$ and the considerable shift in acidity was attributed to the effects of the sulfur ligand and reduction of the $\mathrm{Zn}^{2+}$ coordination number from 6 to 4 . We believe that the hydrated $\mathrm{Zn}^{2+}$ in the TW17 ribozyme also exploits four-folded inner-sphere coordination with the GMPS sulfur as one of its ligands to dramatically decrease the $\mathrm{p} K_{\mathrm{a}}$ of a coordinated water ligand from 9 in this study. However, we do not rule out the possibility that one or more of the ribozyme nucleotides, such as guanine, acts as a general base to facilitate the proton transfer with the hydrated $\mathrm{Zn}^{2+} .8$ Nevertheless, the deprotonated form of the hydrated $\mathrm{Zn}^{2+}$ specifically bound to the TW17 ribozyme active site is well positioned in the alkaline conditions essential to ribozyme catalysis. Interestingly, modern zinc-dependent protein hydrolases also take advantage of the same zinc chemistry to catalyze hydrolytic reactions by using zinc ions to coordinate a nucleophilic water ligand and to lower its $\mathrm{p} K_{\mathrm{a}} \cdot{ }^{\mathbf{1 4 1 5 , 1 7 , 2 5}}$ The current research is thus the first study to raise the possibility that catalytic RNA and protein enzymes could make use of the same fundamental properties of zinc coordination chemistry to accelerate hydrolysis reaction rates.

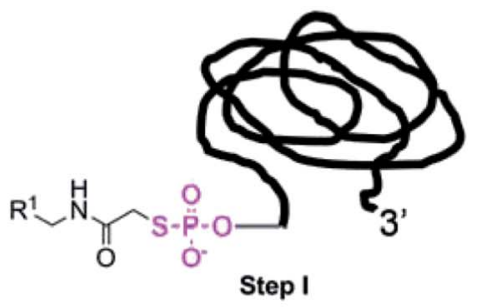

$1 \begin{aligned} & \mathrm{M}^{2+}\left(\mathrm{Zn}^{2+} \text { and } \mathrm{Mg}^{2+}\right) \text {, } \\ & \mathrm{pH} 7.5\end{aligned}$

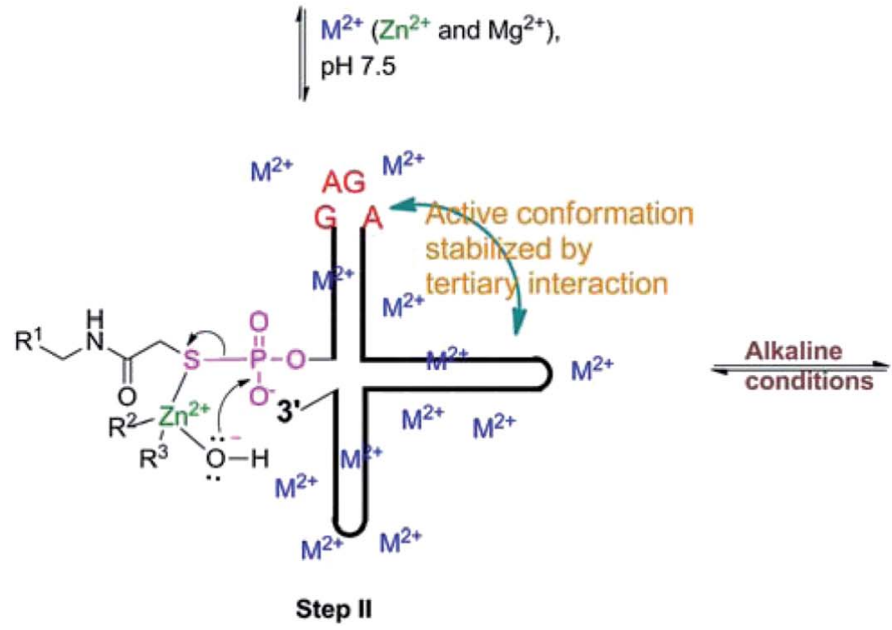

Step II
In addition to the essential functions of $\mathrm{Zn}^{2+}$ and $\mathrm{Mg}^{2+}$ in TW17 ribozyme catalysis, tertiary interactions and partial destabilization of the secondary structure elements in the ribozyme also play distinct roles in the optimal catalytic activity of the TW17 ribozyme. For example, GAGA tetraloop-receptor interaction in the TW17 ribozyme is absolutely required for optimal ribozyme catalysis (Fig. 3 and S6†). Moreover, structural perturbation of the P1 stem, capped by the GAGA tetraloop in the TW17 ribozyme, may promote the ribozyme's sampling of active conformations in order to perform optimal catalysis. The requirement of the partially destabilized P1 stem for the GAGA tetraloop-receptor interaction also substantiates the peculiar observation that incorporating additional base pairs in the P1 stem of the TW17 ribozyme has adverse effects on the interactions of both the substrate-bearing and catalytic TW17 RNA molecules (Table S4 $\dagger$ ). Decreased stability in the secondary structure elements in order to form a tertiary RNA structure has been noted in cooperative RNA folding in the presence of molecular crowders. ${ }^{44}$

We propose the following reaction mechanism of TW17 ribozyme catalysis based on key insights gained from both the metal and $\mathrm{pH}$ titration experiments and also from the secondary and tertiary interaction studies of ribozyme catalysis (Scheme 5). The mononuclear divalent metal ion center of the TW17 ribozyme is proposed to be the deprotonated form of the hydrated $\mathrm{Zn}^{2+}$ (green in Scheme 5) coordinating with the ribozyme by four-folded inner-sphere interactions. In addition, the folding of the TW17 ribozyme to form the proper structure of the catalytic site requires the presence of specifically associated
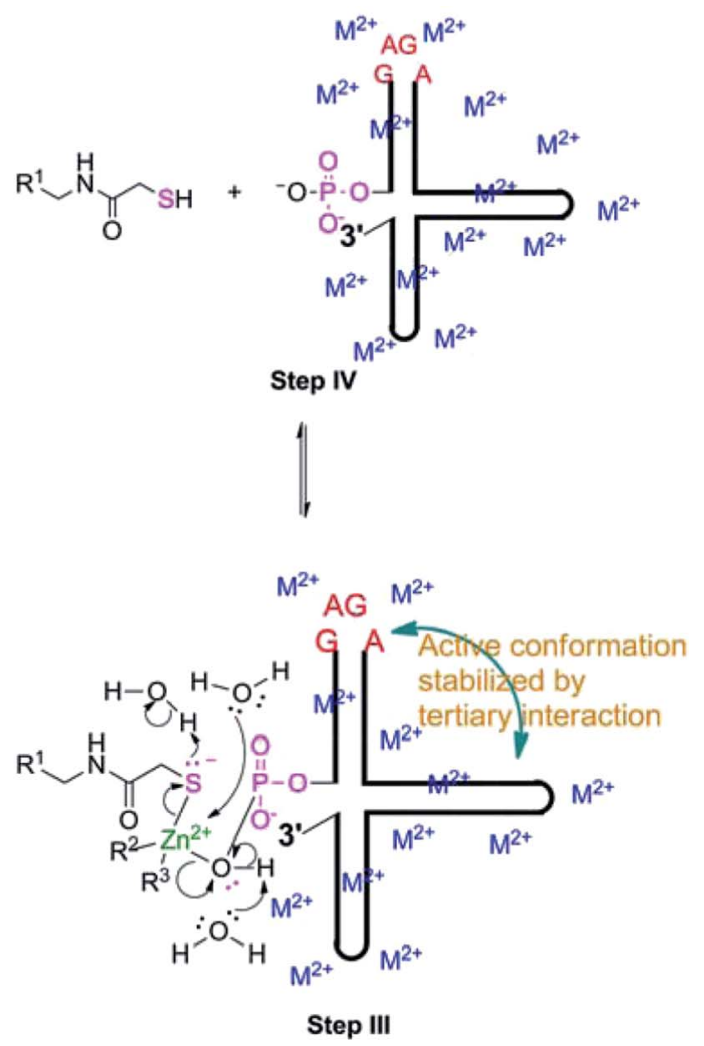

Scheme 5 The proposed mechanism of optimal TW17 ribozyme catalysis. 
inner-sphere and outer-sphere $\mathrm{Mg}^{2+}$ in the ion atmosphere (blue-colored " $\mathrm{M}^{2+}$ " in Scheme 5). Finally, GAGA tetraloopreceptor interaction (cyan-colored curved double arrow in Scheme 5) is also indispensable, and tunes the TW17 ribozyme structure for optimal catalysis.

In the proposed reaction mechanism of TW17 ribozyme catalysis in Scheme 5, the catalytic cycle begins at Step I with the ribozyme structure having no catalytic activity. In the presence of the optimal concentrations of $\mathrm{Zn}^{2+}$ and $\mathrm{Mg}^{2+}\left(\left[\mathrm{Zn}^{2+}\right]=\right.$ $0.5 \mathrm{mM}$ and $\left.\left[\mathrm{Mg}^{2+}\right]=37.5 \mathrm{mM}\right)$, the TW17 ribozyme, aided by the GAGA tetraloop-receptor interaction, folds into the most active conformation (Step II in Scheme 5). The appropriate active structure in alkaline conditions allows the $\mathrm{Zn}^{2+}$-coordinated hydroxide ion to initiate a nucleophilic attack on the adjacent electron-deficient phosphorus in the phosphorothiolate to form a square planar transition state structure which is different from the trigonal bipyramidal structure typically found in self-cleaving ribozyme reactions. ${ }^{5}$ The instability of the transition state structure leads to the breaking of the phosphorothiolate thiolester bond as well as the linkage between the mononuclear $\mathrm{Zn}^{2+}$ and hydroxide (Steps III and IV in Scheme 5). The rapid ligand exchange effected by the properties of $\mathrm{Zn}^{2+}$ facilitates the departing hydroxide ligand in the mononuclear $\mathrm{Zn}^{2+}$ to be simultaneously replaced by a water ligand. Protonation of the thiolate and deprotonation of a water ligand in the mononuclear $\mathrm{Zn}^{2+}$ center are likely achieved by water molecules surrounding the TW17 ribozyme. More structural analysis of the TW17 ribozyme is required to further correlate the results from biochemical studies of ribozyme kinetics with the proposed catalytic mechanism to better comprehend the unique roles of divalent metal ions in ribozyme catalysis.

\section{Conclusion}

We extensively characterized the crucial roles of $\mathrm{Zn}^{2+}, \mathrm{Mg}^{2+}$, and a GAGA tetraloop-receptor interaction in TW17 ribozyme catalysis and confirmed the importance of these concurrent interactions in optimizing the hydrolytic reactions catalyzed by the ribozyme. We accomplished this characterization in four ways. First, we successfully synthesized 6 and 18b, which are each required for the in vitro selection of the TW17 ribozyme, a $\mathrm{Zn}^{2+}$-dependent phosphorothiolate thiolesterase RNA (Scheme 1). Three additional compounds-10a, 10b and 18awere also synthesized and proved to be essential for delineating the chemical mechanism of TW17 ribozyme catalysis and elucidating the critical functions of $\mathrm{Zn}^{2+}, \mathrm{Mg}^{2+}$, and the tertiary interactions in the hydrolytic reaction. The effective organic synthesis of 6 and 18a with good yields permitted the production of ample amounts of the 18a-TW17 ribozyme conjugate, which was necessary to apprehend the $\mathrm{Zn}^{2+}$-dependent catalytic mechanism of the ribozyme. Second, our metal titration studies of TW17 ribozyme catalysis provided strong evidence that the ribozyme requires specifically associated $\mathrm{Zn}^{2+}$ and outer-sphere and inner-sphere equivalences of $\mathrm{Mg}^{2+}$ in the ion atmosphere of the ribozyme for optimal catalysis. Third, we demonstrated a requirement for alkaline conditions for TW17 ribozyme catalysis by measuring the ribozyme activity under various $\mathrm{pH}$ conditions. Fourth, we provided substantial evidence that the tertiary structure formation contributed by the GAGA tetraloopreceptor interaction in the TW17 ribozyme was vital for optimal ribozyme catalysis.

Critical information obtained from the current study leads us to propose that optimal TW17 ribozyme catalysis is a $\mathrm{Zn}^{2+}$. dependent catalytic mechanism, requiring the presence of $\mathrm{Mg}^{2+}$ and a GAGA tetraloop-receptor interaction. We believe that a hydrated $\mathrm{Zn}^{2+}$ ion specifically bound to the TW17 ribozyme has one of its water ligands deprotonated in alkaline conditions and this is essential for ribozyme catalysis. Significantly, it has been well documented that a hydrated zinc plays a similar role in $\mathrm{Zn}$-dependent protein hydrolases involved in group transfer reactions, including hydrolytic reactions. Our current studies of the hydrolytic reaction mechanism catalyzed by the TW17 ribozyme thus suggest that both ribozymes and protein enzymes employ the same zinc coordination chemistry to accelerate the rates of group transfer reactions. Metabolic processes in the primordial RNA world may have taken advantage of the chemical properties of zinc similar to those extensively employed in the catalytic biological reactions of modern living organisms.

\section{Experimental section}

Most reagent-grade chemicals were purchased from commercial sources (Sigma-Aldrich, Acros, Alfa Aesar, Mallinckrodt Baker, and Merck KGaA), and further purified, if necessary. In addition, sulfo-NHS-LC-biotin was acquired from Pierce (Rockford, IL, USA). DEAE Sepharose Fast Flow was purchased from GE Healthcare (Taipei, Taiwan). ${ }^{1} \mathrm{H}$ and ${ }^{13} \mathrm{C}$ NMR spectra were recorded using either a Varian 200 or $400 \mathrm{MHz}$ spectrometer at Kaohsiung Medical University, Taiwan (KMU). NMR samples were prepared in $\mathrm{CD}_{3} \mathrm{OD}, \mathrm{C}_{2} \mathrm{D}_{6} \mathrm{OS}, \mathrm{CDCl}_{3}$, or $\mathrm{D}_{2} \mathrm{O}$; chemical shifts of ${ }^{1} \mathrm{H}$ signals were reported in parts per million downfield from TMS. ${ }^{13} \mathrm{C}$ signals were given in parts per million based on the internal standard of each deuterated solvent. ${ }^{31} \mathrm{P}$ signals were reported as parts per million downfield from $85 \%$ $\mathrm{H}_{3} \mathrm{PO}_{4}$. ESI high-resolution mass spectra were acquired using a Bruker APEX II Fourier-transfer mass spectrometer (FT-MS) at the Department of Chemistry, National Sun Yat-Sen University, Taiwan. FAB high-resolution mass spectra were produced by a JEOL JMS-700 instrument at the Department of Chemistry, National Cheng Kung University, Taiwan.

\section{Synthesis of the ammonium salt of guanosine $\alpha$-thio- monophosphate (6)}

2-Amino-9-((3aR,4R,6R,6aR)-6-hydroxymethyl-2,2-dimethyltetrahydro-furo[3,4-d]-1,3-dioxol-4-yl)-1,9-dihydro-purin-6-one

(2). Guanosine (1; $1 \mathrm{~g}, 3.53 \mathrm{mmol} ; 1$ equiv.) suspended in acetone $(60 \mathrm{~mL})$ was completely dissolved upon the addition of $70 \%$ perchloric acid ( $0.41 \mathrm{~mL}, 4.75 \mathrm{mmol} ; 1.34$ equiv.) to initiate the reaction. The reaction was allowed to proceed at $\mathrm{rt}$ for $70 \mathrm{~min}$, stopped by the addition of $30 \%$ ammonium hydroxide ( $0.67 \mathrm{~mL}, 4.98 \mathrm{mmol} ; 1.40$ equiv.), and then cooled in an ice- 
water bath to afford precipitate. The solid phase was filtered and evaporated in vacuo to give $2(1.13 \mathrm{~g}$; 98\%) as a light-yellow solid. ${ }^{1} \mathrm{H}$ NMR (400 MHz) ( $\left.\mathrm{C}_{2} \mathrm{D}_{6} \mathrm{OS}\right) \delta: 10.69(\mathrm{br}, 1 \mathrm{H}, \mathrm{NH}), 7.92$ (s, $1 \mathrm{H}), 6.51$ (br, 2H, $\mathrm{NH}_{2}$ ), 5.91 (d, 1H), 5.18 (dd, 1H), 4.95 (dd, 1H), 4.11 (ddd, $1 \mathrm{H}), 3.52$ (m, 2H), 1.5 (s, 3H, $\left.\mathrm{CH}_{3}\right), 1.30\left(\mathrm{~s}, 3 \mathrm{H}, \mathrm{CH}_{3}\right)$. ${ }^{13} \mathrm{C}$ NMR (100.67 MHz) ( $\left.\mathrm{C}_{2} \mathrm{D}_{6} \mathrm{OS}\right) \delta: 156.7,153.7,150.7,135.9$, 113.1, 88.4, 86.6, 83.6, 81.2, 61.6, 27.1, 25.2. HRMS (FAB) calculated for $\mathrm{C}_{13} \mathrm{H}_{18} \mathrm{O}_{5} \mathrm{~N}_{5},[\mathrm{M}+\mathrm{H}]^{+} 324.1308$ (calcd), 324.1305 (found).

$O-[(3 a R, 4 R, 6 R, 6 a R)-6-(2-A m i n o-6-0 x o-1,6-d i h y d r o-p u r i n-9-$ yl)-2,2-dimethyl-tetrahydro-furo[3,4- $d]$-1,3-dioxol-4-ylmethyl] ester, sodium salt (3). The synthesis of 3 from 2 followed the procedures used for the synthesis of $\mathbf{4}$ (vide infra) with the exception of the minor modifications described below. Compound 2 ( $0.5 \mathrm{~g}, 1.54 \mathrm{mmol}$; 1 equiv.) was dissolved in dry pyridine $(6 \mathrm{~mL})$ in the presence of a molecular sieve $(0.6 \mathrm{~g} ; 0.3$ $\mathrm{nm}$ ) in an ice-water bath while stirring. Thiophosphoryl chloride $(0.8 \mathrm{~mL}, 7.87 \mathrm{mmol} ; 5.1$ equiv.) was then added to the solution dropwise while stirring over a $5 \mathrm{~min}$ interval. The reaction mixture turned a dark green color after $30 \mathrm{~min}$ of reaction. At this moment, ice $(8 \mathrm{~g})$ accompanied by sodium hydroxide ( $3 \mathrm{~g}, 75 \mathrm{mmol})$ was added and reacted for an additional $30 \mathrm{~min}$. The final reaction mixture was a cloudy yellowwhite solution with a $\mathrm{pH}$ of 6.5 . The remaining procedures were identical to those used for the synthesis of $\mathbf{4}$. Finally, all the precipitates were pooled, washed with acetone, and lyophilized to afford a light-yellow solid of $3(0.18 \mathrm{~g} ; 25 \%)$. The ${ }^{1} \mathrm{H}$ NMR spectrum of 3 was identical to that of 4 . The ${ }^{13} \mathrm{C}$ NMR spectrum and HRMS data of $\mathbf{3}$ are not available due to limited solubility of the compound in $\mathrm{D}_{2} \mathrm{O}$.

$O$-[(3aR,4R,6R,6aR)-6-(2-Amino-6-oxo-1,6-dihydro-purin-9yl)-2,2-dimethyl-tetrahydro-furo[3,4- $d]$-1,3-dioxol-4-ylmethyl] ester, barium salt (4). 2-Amino-9-((3aR,4R,6R,6aR)-6-hydroxymethyl-2,2-dimethyl-tetrahydro-furo[3,4- $d]$-1,3-dioxol-4-yl)-1,9dihydro-purin-6-one (2; $1 \mathrm{~g}, 3 \mathrm{mmol} ; 1$ equiv.) was dissolved in dry pyridine $(6 \mathrm{~mL})$ in the presence of a molecular sieve $(0.6 \mathrm{~g}$; $0.3 \mathrm{~nm})$ in an ice-water bath while stirring. Thiophosphoryl chloride ( $0.8 \mathrm{~mL}, 7.87 \mathrm{mmol} ; 2.6$ equiv.) was then added to the solution dropwise while stirring over a $5 \mathrm{~min}$ interval. The reaction mixture turned a dark green color $30 \mathrm{~min}$ after the addition of thiophosphoryl chloride. Ice $(8 \mathrm{~g})$ accompanied by barium hydroxide octahydrate $(3.8 \mathrm{~g}, 12.05 \mathrm{mmol})$ was subsequently added to the reaction, which was allowed to proceed for an additional $30 \mathrm{~min}$. The final reaction mixture, a cloudy lightyellow solution with a $\mathrm{pH}$ of 6.5 , was separated by centrifugation (13 $000 \mathrm{rpm}, 15 \mathrm{~min}$ ) into two fractions: a yellowish supernatant and a light-yellow precipitate. The supernatant fraction was worked up three times in the following manner: two volumes of 95\% ethanol were added to promote precipitation, followed by centrifuging two times at $13000 \mathrm{rpm}$ for $15 \mathrm{~min}$ to separate the newly acquired precipitate from the supernatant, collecting and pooling the precipitate with the precipitate fraction, and keeping the remaining supernatant for the next workup by repeating the above procedures. The pooled precipitate fraction was washed sequentially with water and pyridine, and ultimately centrifuged at $13000 \mathrm{rpm}$ for $15 \mathrm{~min}$ to separate the precipitate from the supernatant. The afforded supernatant was later worked up twice by the $95 \%$ ethanol precipitation procedures described above to provide a precipitate requiring no further purification. All the precipitates were pooled a second time, washed by acetone, and lyophilized to afford 4 (1.3 g; 75\%) as a light-yellow solid. ${ }^{1} \mathrm{H}$ NMR $(400 \mathrm{MHz})\left(\mathrm{D}_{2} \mathrm{O}\right) \delta: 8.10(\mathrm{~s}, 1 \mathrm{H})$, $6.03(\mathrm{~d}, 1 \mathrm{H}), 5.30$ (dd, 1H), $5.19(\mathrm{dd}, 1 \mathrm{H}), 4.468(\mathrm{~m}, 1 \mathrm{H}), 3.95(\mathrm{~m}$, $2 \mathrm{H}), 1.58(\mathrm{~s}, 3 \mathrm{H}), 1.37(\mathrm{~s}, 3 \mathrm{H})$. The ${ }^{13} \mathrm{C}$ NMR spectrum of 4 is also not available due to limited solubility of the compound in $\mathrm{D}_{2} \mathrm{O}$. HRMS (FAB) calculated for $\mathrm{C}_{13} \mathrm{H}_{17} \mathrm{O}_{7} \mathrm{~N}_{5} \mathrm{PSBa},[\mathrm{M}+\mathrm{H}]^{+} 555.9639$ (calcd), 555.9640 (found).

$O$-[(3aR,4R,6R,6aR)-6-(2-Amino-6-oxo-1,6-dihydro-purin-9yl)-2,2-dimethyl-tetrahydro-furo[3,4- $d]$-1,3-dioxol-4-ylmethyl] ester, ammonium salt (5). $O$-[(3aR,4R,6R,6aR)-6-(2-Amino-6-oxo1,6-dihydro-purin-9-yl)-2,2-dimethyl-tetrahydro-furo[3,4- $d]$-1,3dioxol-4-ylmethyl]ester, barium salt (4; $0.5 \mathrm{~g}, 0.9 \mathrm{mmol}$; 1 equiv.) was dissolved in $10 \mathrm{~mL}$ of water, followed by the addition of ammonium sulfate (0.025 g, $19.7 \mathrm{mmol} ; 21.9$ equiv.). The reaction mixture was stirred at $\mathrm{rt}$ for $1 \mathrm{~h}$, after which the barium sulfate precipitate was removed by centrifugation $(13000 \mathrm{rpm}$, $15 \mathrm{~min}$ ) to afford the desired supernatant. The acquired aqueous phase was mixed with $4-5$ volumes of acetone and centrifuged at $13000 \mathrm{rpm}$ for $15 \mathrm{~min}$ to ensure efficient recovery of the precipitate, which was subsequently lyophilized to afford $5(0.4 \mathrm{~g}, 0.88 \mathrm{mmol} ; 98 \%)$ as a white solid. The ${ }^{1} \mathrm{H}$ spectrum of 5 was also identical to that of 4 . Again, acquisition of the ${ }^{13} \mathrm{C} N M R$ spectrum and HRMS data of $\mathbf{5}$ was not feasible due to the limited solubility of the compound in $\mathrm{D}_{2} \mathrm{O}$.

$O$-[(2R,3S,4R,5R)-5-(2-Amino-6-oxo-1,6-dihydro-purin-9-yl)3,4-dihydroxy-tetrahydro-furan-2-ylmethyl]ester, ammonium salt (6). The ammonium salt of $O-[(3 a R, 4 R, 6 R, 6 a R)-6$-(2-amino6-oxo-1,6-dihydro-purin-9-yl)-2,2-dimethyl-tetrahydro-furo[3,4d]-1,3-dioxol-4-ylmethyl]ester (5; $0.40 \mathrm{~g}, 0.88 \mathrm{mmol})$ was dissolved in $0.4 \mathrm{M} \mathrm{HCl}(5 \mathrm{~mL})$ and stirred at $\mathrm{rt}$ for $1 \mathrm{~h}$. The $\mathrm{pH}$ of the resulting reaction mixture was adjusted to 6.5 by the addition of $30 \%$ ammonium hydroxide, which caused the clear solution to become cloudy. Formation of a white precipitate was further promoted by the addition of 4-5 volumes of acetone to the solution. The cloudy solution was centrifuged at $13000 \mathrm{rpm}$ for $15 \mathrm{~min}$ to separate the precipitate from the remainder of the solution, at which point the supernatant was removed and the precipitate was washed twice with acetone. The precipitate was lyophilized to afford a crude ammonium salt of $O$-[(2R,3S,4R,5R)-5-(2-amino-6-oxo-1,6-dihydro-purin-9-yl)-3,4-dihydroxy-tetrahydro-furan-2-ylmethyl]ester $(6 ; 0.30 \mathrm{~g})$ as a lightyellow solid.

The obtained crude $6(0.30 \mathrm{~g})$ was dissolved in $0.1 \mathrm{M}$ ammonium bicarbonate ( $\mathrm{pH} 8.0 ; 25 \mathrm{~mL}$ ), loaded onto a DEAE Sepharose Fast Flow (GE Healthcare) column, and eluted with 0.1 $\mathrm{M}$ ammonium bicarbonate isocratically. The eluate in each fraction was diluted 100 -fold and the absorbance of each fraction was measured at $253 \mathrm{~nm}$. Fractions with high $A_{253}$ values $(>10)$ were pooled and concentrated by either lyophilizing or reducing the pressure in vacuo. The acquired solid was resuspended in $1.5 \mathrm{~mL}$ of water; the resuspended solid was subsequently subjected to four cycles of the addition of $95 \%$ of ethanol $(20 \mathrm{~mL})$, centrifugation at $13000 \mathrm{rpm}$ for $15 \mathrm{~min}$, and collection of the precipitate in sequence. The final precipitate 
was lyophilized to acquire $6(0.23 \mathrm{~g}, 0.56 \mathrm{mmol}$; 64\%) as a white solid. ${ }^{1} \mathrm{H}$ NMR (400 MHz) ( $\left.\mathrm{D}_{2} \mathrm{O}\right) \delta: 8.16(\mathrm{~s}, 1 \mathrm{H}, \mathrm{NH}), 5.82(\mathrm{~d}, 1 \mathrm{H})$, 4.43 (dd, 1H), 4.25 (m, 1H), 3.96 (m, 1H). ${ }^{13} \mathrm{C} \mathrm{NMR} \mathrm{(100.67} \mathrm{MHz)}$ $\left(\mathrm{C}_{2} \mathrm{D}_{6} \mathrm{OS}\right) \delta: 159.1,154.1,151.9,138.0,116.2,86.8,84.7,74.2$, 71.0, 64.0, 64.0. ${ }^{31} \mathrm{P}$ NMR (161.92 MHz) $\left(\mathrm{D}_{2} \mathrm{O}\right) \delta: 43.65$ (s, 1P). HRMS (FAB) calculated for $\mathrm{C}_{10} \mathrm{H}_{21} \mathrm{O}_{7} \mathrm{~N}_{7} \mathrm{PS},\left[\mathrm{MH}^{+}\right] 414.0961$ (calcd), 414.0962 (found).

\section{Synthesis of substrates for TW17 ribozyme catalysis}

The syntheses of $\mathbf{8 a}, \mathbf{1 2}, \mathbf{1 3}, \mathbf{1 4}, \mathbf{1 5 a}$, and $\mathbf{1 6 a}$ have been reported previously. ${ }^{35}$ However, the detailed procedures for the syntheses of $8 b, 9 a, 9 b, 10 a, 10 b, 15 b, 16 b, 17,18 a$, and $18 b$ are described as follows.

[2-(2-Amino-ethyldisulfanyl)-ethyl]-carbamic acid tert-butyl ester (8b). Cystamine dihydrochloride (7b; $0.41 \mathrm{~g}, 1.81 \mathrm{mmol}$ ), di-tert-butyl dicarbonate $(0.40 \mathrm{~g}, 1.80 \mathrm{mmol})$, and triethylamine $\left(\mathrm{Et}_{3} \mathrm{~N} ; 0.55 \mathrm{~g}, 5.43 \mathrm{mmol}\right)$ were dissolved in methanol (MeOH; 18 $\mathrm{mL}$ ) and reacted at $\mathrm{rt}$ while stirring. ${ }^{34}$ The reaction was allowed to proceed for $30 \mathrm{~min}$ and then stopped by removing $\mathrm{MeOH}$ under reduced pressure. The obtained solid was dissolved in $10 \mathrm{~mL}$ of $1 \mathrm{M} \mathrm{NH}_{2} \mathrm{PO}_{4}$ (pH 4.3); the resulting solution was extracted with ether $(10 \mathrm{~mL})$ twice, adjusted to a $\mathrm{pH}$ of 9 with $1 \mathrm{M} \mathrm{NaOH}$, and extracted five times with $10 \mathrm{~mL}$ EA. The pooled organic phase was dried over $\mathrm{MgSO}_{4}$, filtered, and concentrated under reduced pressure to give oil-like $8 \mathbf{b}(0.18 \mathrm{~g} ; 39.2 \%) .{ }^{1} \mathrm{H}$ NMR (400 MHz) ( $\left.\mathrm{D}_{2} \mathrm{O}\right) \delta: 3.18\left(\mathrm{t}, 2 \mathrm{H}, \mathrm{CH}_{2} \mathrm{NH}\right), 2.74(\mathrm{t}, 2 \mathrm{H}$, $\left.\mathrm{CH}_{2} \mathrm{NH}_{2}\right), 2.61\left(\mathrm{t}, 4 \mathrm{H}, \mathrm{CH}_{2} \mathrm{~S}\right), 1.21\left(\mathrm{~s}, 9 \mathrm{H}, \mathrm{CH}_{3}\right) .{ }^{13} \mathrm{C} \mathrm{NMR}(100.67$ $\mathrm{MHz})\left(\mathrm{D}_{2} \mathrm{O}\right) \delta: 155.72,77.00,42.38,40.50,39.21,38.32$, 28.33. HRMS (ESI) calculated for $\mathrm{C}_{9} \mathrm{H}_{20} \mathrm{~N}_{2} \mathrm{O}_{2} \mathrm{~S}_{2},[\mathrm{M}+\mathrm{H}]^{+} 253.1044$ (calcd), 253.1042 (found).

[6-(2-Bromo-acetylamino)-hexyl]-carbamic acid tert-butyl ester (9a). (6-Amino-hexyl)-carbamic acid tert-butyl ester (8a; $0.256 \mathrm{~g}, 1.18 \mathrm{mmol}$ ) was completely dissolved in DCM (5 mL) in the presence of $\mathrm{Et}_{3} \mathrm{~N}(0.60 \mathrm{~g}, 5.90 \mathrm{mmol})$. Bromoacetyl bromide $(0.60 \mathrm{~g}, 2.95 \mathrm{mmol})$ was then slowly added to this solution in a dropwise manner while stirring at rt. After $1.92 \mathrm{~h}$, the reaction was stopped by removing DCM under reduced pressure. The remaining reaction residue was redissolved in a limited volume of a solution of EA/hexane $(1: 2)$ and loaded onto a preequilibrated silica column. The products were sequentially separated by eluting with solutions of $1: 2,1: 1$, and $2: 1$ ratios of EA to hexane. Fractions containing the desired product were pooled and evaporated under reduced pressure to obtain 9a (0.14 g; 35.5\%). ${ }^{1} \mathrm{H}$ NMR $(400 \mathrm{MHz})\left(\mathrm{CDCl}_{3}\right) \delta: 6.71(\mathrm{~s}, 1 \mathrm{H}$, $\mathrm{NHCOCH}_{2}$ ), 4.66 (s, 1H, OCONH), 4.54 (s, 1H, CONH), 3.88 (s, $2 \mathrm{H}, \mathrm{COCH}_{2} \mathrm{Br}$ ), 3.28 (q, 2H, $\mathrm{CH}_{2} \mathrm{NH}$ ), 3.13 (q, 2H, $\mathrm{CH}_{2} \mathrm{NH}$ ), 1.34$1.56\left(\mathrm{~s}, 9 \mathrm{H}, \mathrm{CH}_{3} ; \mathrm{m}, 8 \mathrm{H}, \mathrm{CH}_{2}\right) .{ }^{13} \mathrm{C} \mathrm{NMR}(100.67 \mathrm{MHz})\left(\mathrm{CDCl}_{3}\right) \delta$ : 165.45, 156.02, 40.67, 40.59, 40.54, 29.87, 28.85, 28.41, 27.15, 26.91. HRMS (ESI) calculated for $\mathrm{C}_{8} \mathrm{H}_{18} \mathrm{BrN}_{2} \mathrm{O}$, $[\mathrm{M}+\mathrm{H}]^{+}$ 237.0602 (calcd), 237.0601 (found).

\{2-[2-(2-Bromo-acetylamino)-ethyldisulfanyl]-ethyl\}carbamic acid tert-butyl ester (9b). [2-(2-Amino-ethyldisulfanyl)ethyl]-carbamic acid tert-butyl ester $(\mathbf{8 b} ; 0.19 \mathrm{~g}, 0.74 \mathrm{mmol})$ was completely dissolved in DMF $(15 \mathrm{~mL})$ in the presence of $\mathrm{Et}_{3} \mathrm{~N}$ $(0.30 \mathrm{~g}, 2.97 \mathrm{mmol})$. The reaction was initiated by the drop-bydrop addition of bromoacetyl bromide $(0.37 \mathrm{~g}, 1.86 \mathrm{mmol})$ to the solution while stirring at rt. The reaction was stopped after $2.45 \mathrm{~h}$ by removing DMF in vacuo. The remaining residue was redissolved in a limited volume of EA/hexane (3:7) solution and loaded onto a pre-equilibrated silica column. The products were sequentially separated by eluting with solutions of $3: 7$, $2: 3$, and $1: 1$ ratios of EA to hexane. Fractions containing $9 \mathbf{b}$ product were pooled, dried over $\mathrm{MgSO}_{4}$, and evaporated under reduced pressure to acquire $9 \mathrm{~b}(0.11 \mathrm{~g} ; 40.2 \%) .{ }^{1} \mathrm{H}$ NMR (400 $\mathrm{MHz})\left(\mathrm{CDCl}_{3}\right) \delta: 7.19\left(\mathrm{~s}, 1 \mathrm{H}, \mathrm{NHCOCH}_{2} \mathrm{Br}\right), 4.99(\mathrm{~s}, 1 \mathrm{H}, 1 \mathrm{H}$, $\mathrm{NHCO}_{2}$ ), 3.90 (s, 2H, COCH ${ }_{2} \mathrm{Br}$ ), 3.63 (q, 2H, $\left.\mathrm{CH}_{2} \mathrm{NHCO}_{2}\right), 3.46$ (q, 2H, $\left.\mathrm{CH}_{2} \mathrm{NHCOCH}_{2}\right), 2.86\left(\mathrm{t}, 2 \mathrm{H}, \mathrm{CH}_{2} \mathrm{CH}_{2} \mathrm{NHCO}_{2}\right), 2.80(\mathrm{t}, 2 \mathrm{H}$, $\left.\mathrm{CH}_{2} \mathrm{CH}_{2} \mathrm{NHCOCH}_{2}\right), 1.45\left(\mathrm{~s}, 9 \mathrm{H}, \mathrm{CH}_{3}\right) .{ }^{13} \mathrm{C} \mathrm{NMR}(100.67 \mathrm{MHz})$ $\left(\mathrm{CDCl}_{3}\right) \delta:$ 165.99, 155.90, 79.74, 39.43, 38.84, 37.98, 37.61, 28.91, 28.37. HRMS (ESI) calculated for $\mathrm{C}_{11} \mathrm{H}_{21} \mathrm{BrN}_{2} \mathrm{O}_{3} \mathrm{~S}_{2},[\mathrm{M}+$ $\mathrm{Na}]^{+} 395.0075$ (calcd), 395.0073 (found).

$\boldsymbol{N}$-(6-Amino-hexyl)-2-bromo-acetamide, TFA salt (10a). [6-(2Bromo-acetylamino)-hexyl]-carbamic acid tert-butyl ester (9a; $0.14 \mathrm{~g}, 0.42 \mathrm{mmol})$ was dissolved in TFA $(7 \mathrm{~mL})$, stirred in an icewater bath for $30 \mathrm{~min}$, and then reacted at $\mathrm{rt}$ for $1 \mathrm{~h}$ while stirring. The products were concentrated under reduced pressure, washed with ether, and concentrated under reduced pressure again to acquire $10 \mathrm{a}(100 \%)$ as a TFA salt. ${ }^{1} \mathrm{H}$ NMR (400 $\mathrm{MHz}$ ( $\left.\mathrm{CD}_{3} \mathrm{OD}\right) \delta: 3.82\left(\mathrm{~s}, 2 \mathrm{H}, \mathrm{COCH}_{2} \mathrm{Br}\right), 3.31\left(\mathrm{t}, 2 \mathrm{H}, \mathrm{CH}_{2} \mathrm{NH}\right)$, $2.92\left(\mathrm{t}, 2 \mathrm{H}, \mathrm{CH}_{2} \mathrm{NH}_{2}\right.$ ), 1.66 (quin, $2 \mathrm{H}, \mathrm{H}_{3} \mathrm{NCH}_{2} \mathrm{CH}_{2}$ ), 1.56 (quin, $\left.2 \mathrm{H}, \mathrm{COHNCH}_{2} \mathrm{CH}_{2}\right), 1.37-1.42\left(\mathrm{~m}, 4 \mathrm{H}, \mathrm{CH}_{2}\right) .{ }^{13} \mathrm{C}$ NMR (100.67 $\mathrm{MHz})\left(\mathrm{CD}_{3} \mathrm{OD}\right) \delta:$ 169.56, 62.55, 77.32, 77.00, 76.68, 40.16, 39.86, 29.85, 29.19, 29.02, 26.13, 26.06. HRMS (ESI) calculated for $\mathrm{C}_{13} \mathrm{H}_{25} \mathrm{BrN}_{2} \mathrm{O}_{3},[\mathrm{M}+\mathrm{Na}]^{+} 359.0946$ (calcd), 359.0949 (found).

$\mathrm{N}$-[2-(2-Amino-ethyldisulfanyl)-ethyl]-2-bromo-acetamide, TFA salt (10b). \{2-[2-(2-Bromo-acetylamino)-ethyldisulfanyl]ethyl-carbamic acid tert-butyl ester $(9 \mathrm{~b} ; 0.11 \mathrm{~g}, 0.30 \mathrm{mmol}$ ) was dissolved in TFA ( $2 \mathrm{~mL})$ and stirred in an ice-water bath for $4 \mathrm{~h}$. The products were concentrated under reduced pressure, washed with ether, and concentrated under reduced pressure again to acquire $10 \mathrm{~b}(100 \%)$ as a TFA salt. ${ }^{1} \mathrm{H}$ NMR $(400 \mathrm{MHz})$ $\left(\mathrm{CD}_{3} \mathrm{OD}\right) \delta: 3.86$ (s, 2H, $\mathrm{COCH}_{2} \mathrm{Br}$ ), 3.55 (sep, $2 \mathrm{H}, \mathrm{CH}_{2} \mathrm{NH}_{3}$ ), 3.31 (q, 2H, $\mathrm{CH}_{2} \mathrm{NHCOCH}_{2}$ ), 2.99 (t, $2 \mathrm{H}, \mathrm{CH}_{2} \mathrm{CH}_{2} \mathrm{NH}_{3}$ ), 2.87 (quin, $\left.2 \mathrm{H}, \mathrm{CH}_{2} \mathrm{CH}_{2} \mathrm{NHCOCH}_{2}\right) .{ }^{13} \mathrm{C} \mathrm{NMR}(100.67 \mathrm{MHz})\left(\mathrm{CD}_{3} \mathrm{OD}\right) \delta$ : 169.76, 62.56, 39.94, 39.33, 37.84, 35.38, 37.61, 28.73. HRMS (ESI) calculated for $\mathrm{C}_{6} \mathrm{H}_{14} \mathrm{BrN}_{2} \mathrm{OS}_{2},[\mathrm{M}+\mathrm{H}]^{+} 272.9731$ (calcd), 272.9733 (found).

[2-(2-\{6-[5-(2-Oxo-hexahydro-thieno[3,4- $d]$ imidazol-4-yl)pentanoylamino]-hexanoylamino\}-ethyldisulfanyl)-ethyl]carbamic acid tert-butyl ester (15b). 6-[5-(2-Oxo-hexahydrothieno[3,4- $d]$ imidazol-4-yl)-pentanoylamino]-hexanoic acid 2,5dioxo-pyrrolidin-1-yl ester $(\mathbf{1 4} ; 0.43 \mathrm{~g}, 0.94 \mathrm{mmol})$ was completely dissolved in DMF (15 mL) with gentle warming. After cooling the solution slowly without reprecipitating 14 , a solution of both $\mathrm{Et}_{3} \mathrm{~N}(0.76 \mathrm{~g}, 7.48 \mathrm{mmol})$ and $\mathbf{8 b}(0.29 \mathrm{~g}, 1.14 \mathrm{mmol})$ in $3 \mathrm{~mL}$ of DMF was added to the solution dropwise while stirring. The reaction proceeded overnight at $\mathrm{rt}$ and the final reaction mixture was filtered, evaporated in vacuo, and loaded onto a pre-equilibrated silica column. The products were sequentially separated by eluting with solutions of $19: 1,9: 1$, and $4: 1$ ratios of DCM/MeOH, dried over $\mathrm{MgSO}_{4}$, filtered, and evaporated under reduced pressure to provide 15b (0.45 g; $81.5 \%)$ as a white solid. ${ }^{1} \mathrm{H}$ NMR $(400 \mathrm{MHz})\left(\mathrm{C}_{2} \mathrm{D}_{6} \mathrm{OS}\right) \delta: 7.97$ (s, 
1H, CONH), $7.76(\mathrm{~s}, 1 \mathrm{H}, \mathrm{CONH}), 7.02(\mathrm{~s}, 1 \mathrm{H}, \mathrm{CONH}), 6.45(\mathrm{~s}, 1 \mathrm{H}$, $\mathrm{CONH}), 6.39(\mathrm{~s}, 1 \mathrm{H}, \mathrm{CONH}), 4.33(\mathrm{t}, 1 \mathrm{H}, \mathrm{CHN}), 4.14(\mathrm{t}, 1 \mathrm{H}$, $\mathrm{CHN}), 3.20\left(\mathrm{t}, 2 \mathrm{H}, \mathrm{CH}_{2} \mathrm{NH}\right), 3.11(\mathrm{dd}, 1 \mathrm{H}, \mathrm{CHS}), 3.01(\mathrm{t}, 2 \mathrm{H}$, $\mathrm{CH}_{2} \mathrm{NH}$ ), 2.83 (d, $\left.1 \mathrm{H}, \mathrm{CHHS}\right), 2.78\left(\mathrm{t}, 4 \mathrm{H}, \mathrm{CH}_{2} \mathrm{~S}\right), 2.74(\mathrm{~d}, 1 \mathrm{H}$, $\mathrm{CHHS}$ ), $2.06\left(\mathrm{t}, 4 \mathrm{H}, \mathrm{CH}_{2} \mathrm{CO}\right), 1.22-1.62(\mathrm{~m}, 21 \mathrm{H}) .{ }^{13} \mathrm{C} \mathrm{NMR}$ $(100.67 \mathrm{MHz})\left(\mathrm{C}_{2} \mathrm{D}_{6} \mathrm{OS}\right) \delta: 172.26,171.81,162.73,155.54,77.82$, $61.05,59.20,55.45,38.31,37.84,37.54,37.37,35.80,35.31$, $35.23,30.79,28.99,28.22,28.04,26.12,25.35,24.99$. HRMS (ESI) calculated for $\mathrm{C}_{25} \mathrm{H}_{45} \mathrm{~N}_{5} \mathrm{O}_{5} \mathrm{~S}_{3},[\mathrm{M}+\mathrm{Na}]^{+} 614.2480$ (calcd), 614.2477 (found).

6-[5-(2-Oxo-hexahydro-thieno[3,4- $d]$ imidazol-4-yl)pentanoylamino]-hexanoic acid [2-(2-amino-ethyldisulfanyl)ethyl]-amide, TFA salt (16b). [2-(2-\{6-[5-(2-Oxo-hexahydrothieno[3,4- $d$ ]imidazol-4-yl)-pentanoylamino]-hexanoylamino\}ethyldisulfanyl)-ethyl]-carbamic acid tert-butyl ester (15b; $0.24 \mathrm{~g}$, $0.39 \mathrm{mmol})$ was dissolved in TFA $(4 \mathrm{~mL})$ and stirred at $\mathrm{rt}$ for $45 \mathrm{~min}$. The products were concentrated under reduced pressure, washed with ether, and concentrated again under reduced pressure to obtain oil-like $16 \mathbf{b}(0.24 \mathrm{~g} ; 100 \%)$ as a TFA salt. ${ }^{1} \mathrm{H}$ NMR (400 MHz) ( $\left.\mathrm{CD}_{3} \mathrm{OD}\right) \delta: 4.54(\mathrm{t}, 1 \mathrm{H}, \mathrm{CHN}), 4.35$ (t, 1H, CHN), 3.56, (t, $4 \mathrm{H}, \mathrm{CH}_{2} \mathrm{NH}$ ), 3.25 (dd, $\left.1 \mathrm{H}, \mathrm{CHS}\right), 3.23$ (t, $2 \mathrm{H}, \mathrm{CH}_{2} \mathrm{NH}$ ), $3.02\left(\mathrm{t}, 2 \mathrm{H}, \mathrm{CH}_{2} \mathrm{~S}\right), 2.96$ (d, $\left.1 \mathrm{H}, \mathrm{CHHS}\right), 2.90\left(\mathrm{t}, 2 \mathrm{H}, \mathrm{CH}_{2} \mathrm{~S}\right), 2.74$ (d, $1 \mathrm{H}, \mathrm{CHHS}), 2.25$ (t, $\left.4 \mathrm{H}, \mathrm{CH}_{2} \mathrm{CO}\right), 1.22-1.78(\mathrm{~m}, 12 \mathrm{H}) \cdot{ }^{13} \mathrm{C}$ NMR (100.67 MHz) (CD $\left.\mathrm{CD}_{3} \mathrm{OD}\right) \delta: 176.40,176.06,159.30,63.40$, $61.65,57.01,41.04,40.17,39.41,38.32,36.90,35.46,30.11$, 29.74, 29.49, 27.48, 26.93, 26.56. HRMS (ESI) calculated for $\mathrm{C}_{20} \mathrm{H}_{37} \mathrm{~N}_{5} \mathrm{O}_{3} \mathrm{~S}_{3},[\mathrm{M}+\mathrm{H}]^{+} 492.2137$ (calcd), 492.2135 (found).

\section{Bromo-acetic acid 2,5-dioxo-pyrrolidin-1-yl ester (17)}

Bromoacetyl bromide $(2.32 \mathrm{~g}, 11.5 \mathrm{mmol})$ was added in a dropwise manner to $15 \mathrm{~mL}$ of a pyridine $(0.91 \mathrm{~g}, 11.5 \mathrm{mmol})$ containing DCM solution (15 mL) while steadily stirring. After $5 \mathrm{~min}$ at $\mathrm{rt}$, the solution became cloudy with the formation of a white precipitate. At this point in the reaction, $N$-hydroxysuccinimide (NHS; $1.32 \mathrm{~g}, 11.5 \mathrm{mmol}$ ) was slowly added to the solution. The reaction was allowed to proceed for an additional $30 \mathrm{~min}$ at $\mathrm{rt}$ while the turbidity of the solution gradually decreased and the solution turned clear. The reaction products were extracted with a saturated solution of sodium bicarbonate twice, $1 \mathrm{M} \mathrm{HCl}$ twice, and a saturated sodium chloride solution once. The final organic phase was dried over $\mathrm{MgSO}_{4}$, filtered, and evaporated under reduced pressure to give 17 (1.42 g; $52.6 \%)$ as a brown solid. ${ }^{1} \mathrm{H}$ NMR $(400 \mathrm{MHz})\left(\mathrm{CDCl}_{3}\right) \delta: 4.10(\mathrm{~s}$, $2 \mathrm{H}, \mathrm{CH}_{2} \mathrm{Br}$ ), 2.87 (s, $4 \mathrm{H}, \mathrm{CH}_{2}$ of NHS). ${ }^{13} \mathrm{C} \mathrm{NMR}(100.67 \mathrm{MHz})$ $\left(\mathrm{CDCl}_{3}\right) \delta: 168.43,162.94,25.53,21.13$. HRMS (ESI) calculated for $\mathrm{C}_{6} \mathrm{H}_{6} \mathrm{O}_{4} \mathrm{NBrNa},[\mathrm{M}+\mathrm{Na}]^{+} 257.9378$ (calcd), 257.9380 (found).

6-[5-(2-Oxo-hexahydro-thieno[3,4- $d]$ imidazol-4-yl)pentanoylamino]-hexanoic acid [6-(2-bromo-acetylamino)hexyl]-amide (18a). Bromo-acetic acid 2,5-dioxo-pyrrolidin-1-yl ester (17; $0.18 \mathrm{~g}, 0.77 \mathrm{mmol})$ dissolved in DMF (1 mL) was dropwise added to a DMF solution $(3 \mathrm{~mL})$ containing both 6-[5(2-oxo-hexahydro-thieno[3,4- $d$ ]imidazol-4-yl)-pentanoylamino]hexanoic acid (6-amino-hexyl)-amide (16a; $0.22 \mathrm{~g}, 0.39 \mathrm{mmol}$ ) and $\mathrm{Et}_{3} \mathrm{~N}(0.13 \mathrm{~g}, 1.32 \mathrm{mmol})$ and stirred at rt. After $3 \mathrm{~h}$, the reaction was stopped by removing DMF in vacuo; the remaining residue was redissolved in a limited volume of a DCM/MeOH
(19:1) solution and loaded onto a pre-equilibrated silica column. The products were sequentially separated by eluting with solutions of $19: 1,9: 1,6: 1$, and $4: 1$ ratios of DCM/ $\mathrm{MeOH}$, dried over $\mathrm{MgSO}_{4}$, filtered, and evaporated under reduced pressure to obtain $18 \mathrm{a}(0.13 \mathrm{~g} ; 58.5 \%)$ as a white solid. ${ }^{1} \mathrm{H}$ NMR (400 MHz) ( $\left.\mathrm{CD}_{3} \mathrm{OD}\right) \delta: 4.52(\mathrm{t}, 1 \mathrm{H}, \mathrm{CHN}), 4.34(\mathrm{t}, 1 \mathrm{H}$, $\mathrm{CHN}$ ), 3.85 (s, $2 \mathrm{H}, \mathrm{CH}_{2} \mathrm{Br}$ ), 3.22 (t, $6 \mathrm{H}, \mathrm{CH}_{2} \mathrm{NH}$ ), 3.22 (dd, $1 \mathrm{H}$, CHS), 2.96 (d, 1H, CHHS), $2.74(\mathrm{~d}, 1 \mathrm{H}, \mathrm{CHHS}), 2.22(\mathrm{t}, 4 \mathrm{H}$, $\left.\mathrm{CH}_{2} \mathrm{CO}\right), 1.40-1.80$ (m, 20H). ${ }^{13} \mathrm{C}$ NMR (100.67 MHz) $\left(\mathrm{CD}_{3} \mathrm{OD}\right) \delta$ : 176.05, 176.00, 169.35, 166.05, 63.38, 61.62, 57.01, 47.91, 41.05, $40.78,40.21,36.99,36.82,30.31,30.12$, 30.05, 29.78, 29.50, 28.84, 27.55, 27.46, 26.93, 26.74. HRMS (ESI) calculated for $\mathrm{C}_{24} \mathrm{H}_{42} \mathrm{BrN}_{5} \mathrm{O}_{4} \mathrm{~S},[\mathrm{M}+\mathrm{Na}]^{+} 598.2038$ (calcd), 598.2040 (found).

6-[5-(2-Oxo-hexahydro-thieno[3,4-d] imidazol-4-yl)pentanoylamino]-hexanoic acid $\{2$-[2-(2-bromo-acetylamino)ethyldisulfanyl]-ethyl $\}$-amide (18b). Bromo-acetic acid 2,5-dioxopyrrolidin-1-yl ester (17; $0.18 \mathrm{~g}, 0.74 \mathrm{mmol}$ ) dissolved in DMF $(0.8 \mathrm{~mL})$ was added dropwise with continuous stirring to a DMF solution $(3.2 \mathrm{~mL})$ containing $\mathrm{Et}_{3} \mathrm{~N}(0.09 \mathrm{~g}, 0.93 \mathrm{mmol})$ and 6-[5-(2-oxo-hexahydro-thieno[3,4- $d]$ imidazol-4-yl)-pentanoylamino]-hexanoic acid [2-(2-amino-ethyldisulfanyl)-ethyl]-amide (16b; $0.22 \mathrm{~g}, 0.37 \mathrm{mmol}$ ) at rt. The reaction was stopped after $2.25 \mathrm{~h}$ by removing DMF in vacuo; the remaining residue was redissolved in a limited volume of $19: 1 \mathrm{DCM} / \mathrm{MeOH}$ solution and loaded onto a pre-equilibrated silica column. The products were sequentially separated by eluting with solutions of $19: 1,9: 1,6: 1$, and $4: 1$ ratios of $\mathrm{DCM} / \mathrm{MeOH}$, dried over $\mathrm{MgSO}_{4}$, filtered, and evaporated under reduced pressure to yield $18 \mathrm{~b}(0.047 \mathrm{~g} ; 20.6 \%)$ as a white solid. ${ }^{1} \mathrm{H}-\mathrm{NMR}(400 \mathrm{MHz})\left(\mathrm{CD}_{3} \mathrm{OD}\right) \delta: 4.50(\mathrm{t}, 1 \mathrm{H}, \mathrm{CHN}), 4.32(\mathrm{t}, 1 \mathrm{H}$, $\mathrm{CHN}$ ), 3.85 (s, 2H, $\mathrm{CH}_{2} \mathrm{Br}$ ), 3.51 (t, $4 \mathrm{H}, \mathrm{CH}_{2} \mathrm{NH}$ ), 3.22 (dd, 1H, CHS), 3.19 (t, 2H, $\left.\mathrm{CH}_{2} \mathrm{NH}\right), 2.93$ (d, 1H, CHHS), 2.84 (t, 4H, $\left.\mathrm{CH}_{2} \mathrm{~S}\right), 2.71$ (d, $1 \mathrm{H}, \mathrm{CHHS}), 2.21$ (t, 4H, $\left.\mathrm{CH}_{2} \mathrm{CO}\right), 1.31-1.75(\mathrm{~m}, 12 \mathrm{H}) .{ }^{13} \mathrm{C}-\mathrm{NMR}$ $(100.67 \mathrm{MHz})\left(\mathrm{CD}_{3} \mathrm{OD}\right) \delta: 176.31,176.00,173.95,164.80,63.38$, $61.63,57.00,41.05,40.20,39.95,39.45,38.54,37.45,36.90,36.83$, 30.11, 29.77, 29.49, 27.53, 26.91, 26.59. HRMS (FAB) calculated for $\mathrm{C}_{22} \mathrm{H}_{39} \mathrm{O}_{4} \mathrm{~N}_{5} \mathrm{BrS}_{3},[\mathrm{M}+\mathrm{H}]^{+} 612.1348$ (calcd), 612.1348 (found).

\section{TW17 ribozyme synthesis and purification}

Both the 5' GMPS-primed TW17 RNA (87-mer; 5'-GGGAUCGUCAGUGCAUUGAGAAGUGCAGUGUCUUGCGCUGGGUUCGAGCGGUCCGUGGUGCUGGCCCGGUGGUAUCCCCAAGGGGUA-3') and the TW17 RNA body-labeled with ${ }^{32} \mathrm{P}$ were prepared according to the previously reported method. ${ }^{18}$ Radio-labeled TW17 ribozyme substrate conjugates and their reaction products were analyzed using either urea-polyacrylamide gel electrophoresis (urea-PAGE) or streptavidin (SAv) gel-shift assays in urea-PAGE, visualized, and quantified by an Amersham Typhoon PhosphorImager at KMU. All the aqueous solutions were prepared from diethyl pyrocarbonate (DEPC)-treated water to prevent RNA degradation.

\section{General kinetics of TW17 ribozyme catalysis}

The procedures for measuring the kinetics of TW17 ribozyme catalysis under a standard condition have been reported previously ${ }^{18}$ but are briefly described below. The ${ }^{32} \mathrm{P}$-bodylabeled TW17 ribozyme was initially dissolved in EK buffer 
(50 mM EPPS, $500 \mathrm{mM} \mathrm{KCl,} \mathrm{pH} \mathrm{7.5),} \mathrm{heated} \mathrm{at} 95{ }^{\circ} \mathrm{C}$ for $1 \mathrm{~min}$, centrifuged, and then cooled at rt for $10 \mathrm{~min}$ to allow the RNA to refold in the absence of metal ions. $\mathrm{Mg}^{2+}$ and $\mathrm{Zn}^{2+}$ were then added sequentially in $5 \mathrm{~min}$ intervals to the RNA solution to commence TW17 ribozyme catalysis at rt. The reaction mixture for the standard TW17 ribozyme catalysis contained $1 \mu \mathrm{M}$ of the ribozyme, $100 \mathrm{mM} \mathrm{MgCl}_{2}$, $0.5 \mathrm{mM} \mathrm{ZnCl}_{2}$, and $0.24 \%$ Triton X100 in EK buffer. Aliquots were removed from the reaction mixture at indicated times during the course of the reaction and purified twice by ethanol precipitation. The purified samples were resolved by SAv gel shift assays utilizing 8\% urea-PAGE and analyzed by an Amersham Typhoon PhosphorImager system. The resulting data were fitted into a single-exponential equation for first-order kinetics $F(t)=F_{0}+F_{\max }\left(1-\mathrm{e}^{-k_{\mathrm{obs}} t}\right)[F(t)$, percent cleavage of the reactant at a specific time point $t]$ to acquire the first-order rate constant $k_{\text {obs }}$ (GraphPad, La Jolla, CA, USA).

\section{Metal titration}

The metal titration experiments were performed by following the procedures stated in the previous section except that the divalent metal ions were replaced by different combinations and concentrations of $\mathrm{Zn}^{2+}, \mathrm{Mg}^{2+}$, or $\left[\mathrm{Co}\left(\mathrm{NH}_{3}\right)_{6}\right]^{3+}$. Solid magnesium chloride was dissolved in DEPC-treated water to prepare a $2 \mathrm{M} \mathrm{Mg}^{2+}$ stock solution, which was stored at $-20{ }^{\circ} \mathrm{C}$. A $200 \mathrm{mM} \mathrm{Zn}^{2+}$ stock solution was prepared by dissolving $\mathrm{ZnCl}_{2}(\mathrm{~s})$ in DEPC-treated water and stored at $-20{ }^{\circ} \mathrm{C}$. The stock solution of $40 \mathrm{mM}\left[\mathrm{Co}\left(\mathrm{NH}_{3}\right)_{6}\right]^{3+}$ was similarly obtained by dissolving $\left[\mathrm{Co}\left(\mathrm{NH}_{3}\right)_{6}\right] \mathrm{Cl}_{3}(\mathrm{~s})$ in DEPC-treated water and storing at $-20{ }^{\circ} \mathrm{C}$. Analyses of $\mathrm{Zn}^{2+}$ titration in the presence of $100 \mathrm{mM}$ $\mathrm{Mg}^{2+}$ were performed by substituting various concentrations of $\mathrm{Zn}^{2+}(0.13-10 \mathrm{mM})$ for $0.5 \mathrm{mM} \mathrm{Zn}^{2+}$ in the kinetic analysis reaction mixtures. For kinetic analyses of ribozyme catalysis in the absence of $100 \mathrm{mM} \mathrm{Mg}{ }^{2+}$, several concentrations of $\mathrm{Zn}^{2+}$ ranging from 0.13 to $1.88 \mathrm{mM}$ were substituted for the $0.5 \mathrm{mM}$ $\mathrm{Zn}^{2+}$ used in the standard reaction mixtures. Alternatively, in the presence of $0.5 \mathrm{mM} \mathrm{Zn}^{2+}$, the $100 \mathrm{mM} \mathrm{Mg}^{2+}$ in the standard kinetic condition was replaced by several concentrations of $\mathrm{Mg}^{2+}$ (1-100 mM), and TW17 ribozyme catalysis was measured. Finally, catalysis measurements analyzing $\left[\mathrm{Co}\left(\mathrm{NH}_{3}\right)_{6}\right]^{3+}$ titration in the presence of $0.5 \mathrm{mM} \mathrm{Zn}^{2+}$ were performed by replacing the $100 \mathrm{mM} \mathrm{Mg}^{2+}$ required for the standard kinetic condition in TW17 ribozyme catalysis with concentrations of $\left[\mathrm{Co}\left(\mathrm{NH}_{3}\right)_{6}\right]^{3+}$ between 1 and $500 \mu \mathrm{M}$. In each kinetic analysis, the duration of the reactions ranged from 3 to $24 \mathrm{~h}$ in order to ensure the firstorder reaction reached a maximal product yield. Each $k_{\text {obs }}$ value was acquired by fitting data into the single-exponential equation for the first-order kinetics described previously [general kinetics of TW17 ribozyme catalysis]. A reported rate constant was determined by calculating the average of the rates from triplicate experiments accompanied with the standard deviations. The obtained values of $k_{\mathrm{obs}}$ from concentrations of substituted $\mathrm{Zn}^{2+}$ ions $\left\{\left[\mathrm{M}^{n+}\right]\right\}$, were fitted into the Hill equation $k_{\text {obs }}=\left\{\left[\left(k_{\text {obs }}\right)_{\text {max }}\right]\left[\mathrm{M}^{n+}\right]^{h}\right\} /\left\{K_{\mathrm{d}}+\left[\mathrm{M}^{n+}\right]^{h}\right\}$ to attain $K_{\mathrm{d}}$ (average dissociation constant for a TW17 ribozyme- $\mathbf{M}^{n+}$ complex at equilibrium) and the Hill coefficient $h$, which was calculated as the minimum $\mathbf{M}^{n+}$ equivalence essential to TW17 ribozyme catalysis (GraphPad).

\section{pH-dependent kinetics}

As was the case for the metal titration experiments, $\mathrm{pH}$ titration studies of TW17 ribozyme catalysis were also carried out by following previously described procedures [general kinetics for TW17 ribozyme catalysis] except that various $\mathrm{pH}$ buffer solutions were substituted for the EK buffer in the reaction mixtures. Buffers for the $\mathrm{pH}$ titration studies were MES (pH 5.56.5), PIPES ( $\mathrm{pH}$ 6.5-7.5), or EPPS (7.5-8.5); each buffer also contained $500 \mathrm{mM} \mathrm{KCl}$. As in the metal titration experiments, reaction times of 3 to $24 \mathrm{~h}$ were required to ensure that the firstorder reaction reached a maximal product yield. Each $k_{\text {obs }}$ value was acquired by fitting data into the single-exponential equation for the first-order kinetics [general kinetics of TW17 ribozyme catalysis]. A reported rate constant accompanied by a standard deviation represented the average of rates obtained from the kinetic experiments performed in triplicate. Values of $k_{\text {obs }}$ obtained from TW17 ribozyme catalysis under different $\mathrm{pH}$ conditions were fitted into the equation for general base catalysis, ${ }^{40} k_{\mathrm{obs}}=\left[\left(k_{\mathrm{obs}}\right)_{\max }\right] /\left[1+10^{\left(\mathrm{p} K_{\mathrm{a}}-\mathrm{pH}\right)}\right]$, but were unable to provide reasonable values of $\mathrm{p} K_{\mathrm{a}}$ for a general base and $k_{\mathrm{obs} \text {,max }}$ in the presence of the general base.

\section{Preparation of RNA molecules for Langmuir isotherm study and trans-phosphorothiolate thiolesterase assay of trans- acting TW17 ribozyme systems}

Ten bimolecular trans-acting TW17 ribozyme systems were prepared by following the previously reported methods ${ }^{\mathbf{1 8}}$ and are described in Table S1 (ESI $\dagger$ ). Binary RNA binding affinities in the bimolecular trans-acting TW17 ribozyme systems were determined for eight pairs of constructs: TW17S-1 RNA + TW17C-1 RNA, TW17S-2 RNA + TW17C-2 RNA, TW17S-3 RNA + TW17C-3 RNA, TW17S-4 RNA + TW17C-4 RNA, TW17S-5 RNA + TW17C-5 RNA, TW17S-6 RNA + TW17C-5 RNA, TW17S-1 RNA + TW17C-5 RNA, and TW17S-2 RNA + TW17C-3 RNA systems. In addition, the trans-phosphorothiolate thiolesterase activities of the two TW17 ribozyme systems, TW17S ${ }_{1-29}$ RNA + TW17C $_{30-87}$ RNA and TW17S $1-29$ RNA + TW17C $22-87$ RNA, were measured. Primers required for the construction of the trans-acting TW17 ribozyme systems can be found in Table S2 (ESI $\dagger$ ).

\section{Langmuir isotherm study to determine binding affinities in trans-acting TW17 ribozyme systems}

The Langmuir isotherm study of the TW17S-1 + TW17C-1 system provides a generic description of the binding affinity experiments performed using trans-acting TW17 ribozyme systems. The ${ }^{32} \mathrm{P}$-body-labeled TW17S-1 RNA was dissolved in $4 \mathrm{X}$ EK buffer (200 mM EPPS, $2 \mathrm{M} \mathrm{KCl,} \mathrm{pH} \mathrm{7.5)} \mathrm{in} \mathrm{the} \mathrm{presence} \mathrm{of}$ varying concentrations of $\mathrm{Zn}^{2+}(2.25-75 \mathrm{mM})$ to give the $0.14 \mu \mathrm{M}$ TW17S-1 RNA solutions used in all the binding affinity assays (Table S3; ESI $\dagger$ ). The concentration of $\mathrm{Zn}^{2+}$ in a $0.14 \mu \mathrm{M}$ TW17S1 solution was determined by multiplying $2.25 \mathrm{mM}$ by the molar ratio of TW17C-1 RNA to TW17S-1 RNA. However, the $\left[\mathrm{Zn}^{2+}\right]$ in the $0.14 \mu \mathrm{M}$ TW17S-1 solutions was held constant at $2.25 \mathrm{mM}$ 
when the molar ratio of TW17C-1 RNA to TW17S-1 RNA was less than 1. Conversely, the label-free TW17C-1 RNA was dissolved in $4 \mathrm{X}$ EK buffer in the presence of varied concentrations of $\mathrm{Mg}^{2+}$ $(0-780 \mathrm{mM})$ to yield the $0-7.0 \mu \mathrm{M}$ TW17C-1 RNA solutions (Table S3; ESI $\dagger$ ) also essential for performing the binding affinity assays. The concentration of $\mathrm{Mg}^{2+}$ in the TW17C-1 solution was determined by multiplying $94 \mathrm{mM}$ with the molar ratio of TW17C-1 RNA to TW17S-1 RNA. However, the TW17C-1 solutions always had a $\left[\mathrm{Mg}^{2+}\right]$ equal to $94 \mathrm{mM}$ when the molar ratio of TW17C-1 RNA to TW17S-1 RNA was less than one, and a $\mathrm{Mg}^{2+}$ concentration of $780 \mathrm{mM}$ when the molar ratio of TW17C-1 RNA to TW17S-1 RNA was higher than 20 due to the limited solubility of $\mathrm{MgCl}_{2}$ when solutions with a $\left[\mathrm{Mg}^{2+}\right]>3 \mathrm{M}$ were prepared.

The acquired TW17S-1 RNA and TW17C-1 RNA solutions were boiled at $95^{\circ} \mathrm{C}$ for $1 \mathrm{~min}$, cooled at $\mathrm{rt}$ for $10 \mathrm{~min}$, mixed in a $1: 1(\mathrm{v} / \mathrm{v})$ ratio, and reacted at $\mathrm{rt}$ for $30 \mathrm{~min}$. The afforded binding reaction products were separated using $10 \%$ nondenaturing PAGE at $4 \mathrm{~W}$ for $70 \mathrm{~min}$ and analyzed by an Amersham Typhoon PhosphorImager system. The non-denaturing PAGE apparatus was surrounded by ice during electrophoresis in order to reduce the effects of a temperature increase caused by heat generated during electrophoresis. Percent binding values $(Y)$ from specific concentrations of TW17C-1 RNA ([TW17C-1 RNA]) were fitted according to the Langmuir isotherm equation $\left\{Y=\left(Y_{\max } \times[\right.\right.$ TW17C-1 RNA $\left.]\right) /\left(K_{\mathrm{d}}+[\right.$ TW17C1 RNA])\} to attain $K_{\mathrm{d}}$ (the dissociation constant for the TW17S-1 RNA-TW17C-1 RNA complex at equilibrium) and $Y_{\max }$, which is the maximum percent binding of TW17S-1 RNA to TW17C-1 RNA (GraphPad).

\section{Trans-phosphorothiolate thiolesterase assay}

Multiple substrate turnover analysis of the trans-phosphorothiolate thiolesterase reaction in the $\mathrm{TW}_{17 \mathrm{~S}_{1-29}} \mathrm{RNA}+$ TW17C $_{30-87}$ RNA and TW17S ${ }_{1-29}$ RNA + TW17C $_{22-87}$ RNA systems was carried out according to procedures previously described. ${ }^{18}$ The initial velocity for each catalytic reaction in the presence of a specific concentration of the ${ }^{32} \mathrm{P}$-labeled $\mathrm{S}_{1-29}$ RNA-18a conjugate was studied by nonlinear least-square curve fitting to the Michaelis-Menten equation $\left\{v=\left(V_{\max } \times\left[\mathrm{S}_{1-29}\right.\right.\right.$ $\left.\mathrm{RNA}]) /\left(K_{\mathrm{M}}+\left[\mathrm{S}_{1-29} \mathrm{RNA}\right]\right)\right\}$, but were unable to provide reasonable values of $K_{\mathrm{M}}, k_{\text {cat }}$, and $k_{\text {cat }} / K_{\mathrm{M}}(\mathrm{GraphPad})$.

\section{Conflicts of interest}

There are no conflicts to declare.

\section{Acknowledgements}

We thank Dr Susan Fetzer for critically reading the manuscript. We also thank the Center for Research Resources and Development of KMU for technical and instrumental assistance. This work was supported with funding from the National Science Council of Taiwan (NSC 96-2113-M-037-004-MY2 and NSC 1002113-M-037-008-) and the Ministry of Science and Technology of Taiwan (MOST 103-2113-M-037-010-) awarded to T.-P. W.

\section{References}

1 T. R. Cech, Cell, 2009, 136, 599-602.

2 T. J. Wilson and D. M. J. Lilley, Science, 2009, 323, 1436-1438.

3 W. E. Draper, E. J. Hayden and N. Lehman, Nucleic Acids Res., 2008, 36, 520-531.

4 R. K. O. Sigel and A. M. Pyle, Chem. Rev., 2007, 107, 97-113.

5 M. J. Fedor, Annu. Rev. Biophys., 2009, 38, 271-299.

6 K. M. Brooks and K. J. Hampel, Biochemistry, 2011, 50, 24242433.

7 D. M. J. Lilley, Biochem. Soc. Trans., 2017, 45, 683-691.

8 E. A. Frankel, C. A. Strulson, C. D. Keating and P. C. Bevilacqua, Biochemistry, 2017, 56, 2537-2548.

9 G. S. Manning, J. Chem. Phys., 1969, 51, 934-938.

10 Y. Bai, M. Greenfeld, K. J. Travers, V. B. Chu, J. Lipfert, S. Doniach and D. Herschlag, J. Am. Chem. Soc., 2007, 129, 14981-14988.

11 M. Gebala, G. M. Giambașu, J. Lipfert, N. Bisaria, S. Bonilla, G. Li, D. M. York and D. Herschlag, J. Am. Chem. Soc., 2015, 137, 14705-14715.

12 D. E. Draper, $R N A, 2004,10,335-343$.

13 J. Lipfert, S. Doniach, R. Das and D. Herschlag, Annu. Rev. Biochem., 2014, 83, 813-841.

14 D. S. Auld, BioMetals, 2001, 14, 271-313.

15 B. L. Vallee and D. S. Auld, Proc. Natl. Acad. Sci. U. S. A., 1990, 87, 220-224.

16 C. E. Outten and T. V. O'Halloran, Science, 2001, 292, 24882492.

17 K. A. McCall, C.-C. Huang and C. A. Fierke, J. Nutr., 2000, 130, 1437S-1446S.

18 T.-P. Wang, Y.-C. Su, Y. Chen, Y.-M. Liou, K.-L. Lin, E.-C. Wang, L.-C. Hwang, Y.-M. Wang and Y.-H. Chen, Biochemistry, 2012, 51, 496-510.

19 A. Furukawa, T. Maejima, S. Matsumura and Y. Ikawa, Biosci., Biotechnol., Biochem., 2016, 80, 1386-1389.

20 L. Jaeger, F. Michel and E. Westhof, J. Mol. Biol., 1994, 236, 1271-1276.

21 S. E. Butcher and A. M. Pyle, Acc. Chem. Res., 2011, 44, 13021311.

22 J. Ishikawa, Y. Fujita, Y. Maeda, H. Furuta and Y. Ikawa, Methods, 2011, 54, 226-238.

23 H. Furusawa, S. Fukusho and Y. Okahata, ChemBioChem, 2014, 15, 865-871.

24 C. R. Woese, S. Winker and R. R. Gutell, Proc. Natl. Acad. Sci. U. S. A., 1990, 87, 8467-8471.

25 M. Hernick and C. Fierke, Arch. Biochem. Biophys., 2005, 433, 71-84.

26 E. Veliath, B. L. Gaffney and R. A. Jones, Nucleosides, Nucleotides Nucleic Acids, 2014, 33, 40-52.

27 M. Strenkowska, P. Wanat, M. Ziemniak, J. Jemielity and J. Kowalska, Org. Lett., 2012, 14, 4782-4785.

28 M. Olesiak, D. Krajewska, E. Wasilewska, D. KorczyŇski, J. Baraniak, A. Okruszek and W. J. Stec, Synlett, 2002, 0967-0971.

29 E. J. Behrman, J. Chem. Res., 2000, 446-447. 
30 B. Fischer, A. Chulkin, J. L. Boyer, K. T. Harden, F. P. Gendron, A. R. Beaudoin, J. Chapal, D. Hillaire-Buys and P. Petit, J. Med. Chem., 1999, 42, 3636-3646.

31 A. B. Burgin and N. R. Pace, EMBO J., 1990, 9, 4111-4118.

32 B. Zhang, Z. Cui and L. Sun, Org. Lett., 2001, 3, 275-278.

33 M. Oivanen, M. Ora, H. Almer, R. Stromberg and H. Lonnberg, J. Org. Chem., 1995, 60, 5620-5627.

34 K. A. Jacobson, B. Fischer and X. D. Ji, Bioconjugate Chem., 1995, 6, 255-263.

35 T.-P. Wang, Y.-J. Chiou, Y. Chen, E.-C. Wang, L.-C. Hwang, B.-H. Chen, Y.-H. Chen and C.-H. Ko, Bioconjugate Chem., 2010, 21, 1642-1655.

36 X. Fang, T. Pan and T. R. Sosnick, Biochemistry, 1999, 38, 16840-16846.

37 S. K. Silverman and T. R. Cech, Biochemistry, 1999, 38, 86918702 .
38 V. B. Chu, Y. Bai, J. Lipfert, D. Herschlag and S. Doniach, Curr. Opin. Chem. Biol., 2008, 12, 619-625.

39 J. Weiss, FASEB J., 1997, 11, 835-841.

40 S. Nakano, D. M. Chadalavada and P. C. Bevilacqua, Science, 2000, 287, 1493-1497.

41 K. S. Koutmou, A. Casiano-Negroni, M. M. Getz, S. Pazicni, A. J. Andrews, J. E. Penner-Hahn, H. M. Al-Hashimi and C. A. Fierke, Proc. Natl. Acad. Sci. U. S. A., 2010, 107, 24792484.

42 H. Sigel and R. B. Martin, Chem. Soc. Rev., 1994, 23, 83-91.

43 C. P. Da Costa, A. Okruszek and H. Sigel, ChemBioChem, 2003, 4, 593-602.

44 K. A. Leamy, N. H. Yennawar and P. C. Bevilacqua, Biochemistry, 2017, 56, 3422-3433. 